Bolm Inst. oceanogr., S Paulo, 25:1-28, 1976

\title{
CONSIDERAÇÕES SOBRE A CAPTURA DE PEIXES POR UM CERCO FIXO EM CANANEEIA, SÃO PAULO, BRASIL
}

\author{
ALEXANDER RADASEWSKY \\ Instituto Oceanográfico da Universidade de São Paulo
}

\section{SYNOPSIS}

This paper presents the results of observations carried on during the period 1964-1967 on fish captured by a fixed fish-trap, located in the Lagoon of Cananéia, São Paulo, Brazil.

The local catch consisted mainly on two species: "carapeba" (Diapterus rhombeus) and "tainha" (Mugil cephalus). Nine out of the 32 species captured in 1967 were studied in detail. Specimens of sexually matured "taînha" were present in a well defined period, from April to August, so that one may assume the possibility of spawning at that time. This period agrees with the minimum water temperature and local commercial fishing trap operations.

The size of first sexual maturation was observed in six different species, respectively for male and female, "carapeba", 13 and $12 \mathrm{~cm}$; "taînha", 33 and $38 \mathrm{~cm}$; "parati" (Mugil curema), 28 and $30 \mathrm{~cm}$; "paru" (Pomocanthus arcuatus), 11 and $13 \mathrm{~cm}$; "robalo" (Centropomus paralellus), 24 and $16 \mathrm{~cm}$; and $18 \mathrm{~cm}$ for female of "sargo-de-dentes" (Archosargus aries).

This kind of fishing was influenced by meteorological and hydrographic conditions, mainly by water temperature and salinity. 
INTRODUÇÃO

0 presente trabalho objetiva fornecer informações sobre a composição da captura de um cerco fixo instalado na região lagunar de Cananéia, junto à Base Sul do Instituto Oceanogrāfico da Universidade de São Paulo.

Procurou-se verificar a possível influência de fatores hidrogräficos e meteorológicos sobre a composição da captura, o comportamento dos peixes em relação ao cerco fixo e a maturação sexual dos mesmos, bem como o comprimento médio de início da primeira maturação sexual.

Finalmente, objetivou-se relacionar os dados obtidos no presente trabalho com as atividades da pesca comercial da região, visando contribuir para o seu entendimento.

MATERIAL E MËTODOS

A parte experimental foi efetuada com capturas de pescado através de um cerco fixo (Figs 1-2) instalado junto à Base Sul, na região lagunar de Cananéia $\left(25^{\circ} 00^{\prime} 57^{\prime \prime}\right.$ s e $047^{\circ} 55^{\prime} 35^{\prime \prime}$ W) (Fig. 3).

\section{CERCO FIXO E PESCA -}

0 aparelho de captura utilizado è uma armadilha fixa, que na sistematização de Brandt (1959) pertence à classe de "fish traps", sub classe "fish edges". Sua construção foi efetuada com varas de madeira com diâmetro de aproximadamente $5 \mathrm{~cm}$, instaladas a uma distância de $50 \mathrm{~cm}$ uma da outra, 
ligadas entre si nas partes superior, média e inferior por meio de arcos de madeira. Os espaços entre as varas foram preenchidos com taquara mirim (Philostatis aurea) ou com bambū cortado longitudinalmente. Todo o conjunto foi reforçado com tela de arame galvanizado, com malhas de $4 \mathrm{~cm}$ entre dois ângulos, o que dā uma abertura de malha de $5 \mathrm{~cm}$, aproximadamente (Fig. 2).

A retirada dos peixes foi realizada com o auxílio de uma rede cuja a1tura e largura correspondem às dimensões do cerco, e nas extremidades, estão fixadas varas de bambū ligadas entre si por uma linha forte que corre dentro de anéis metālicos, o que permite fechar a rede como uma bolsa. Nessa operação a rede foi arrastada por duas pessoas ao longo das paredes do cerco fixo e, uma vez fechado o círculo, a rede foi levantada e os peixes acondicionados em uma embarcação de transporte. O processo foi repetido atē que a retirada dos peixes fosse completa, tendo sido efetuado semanalmente de 1964 a 1967

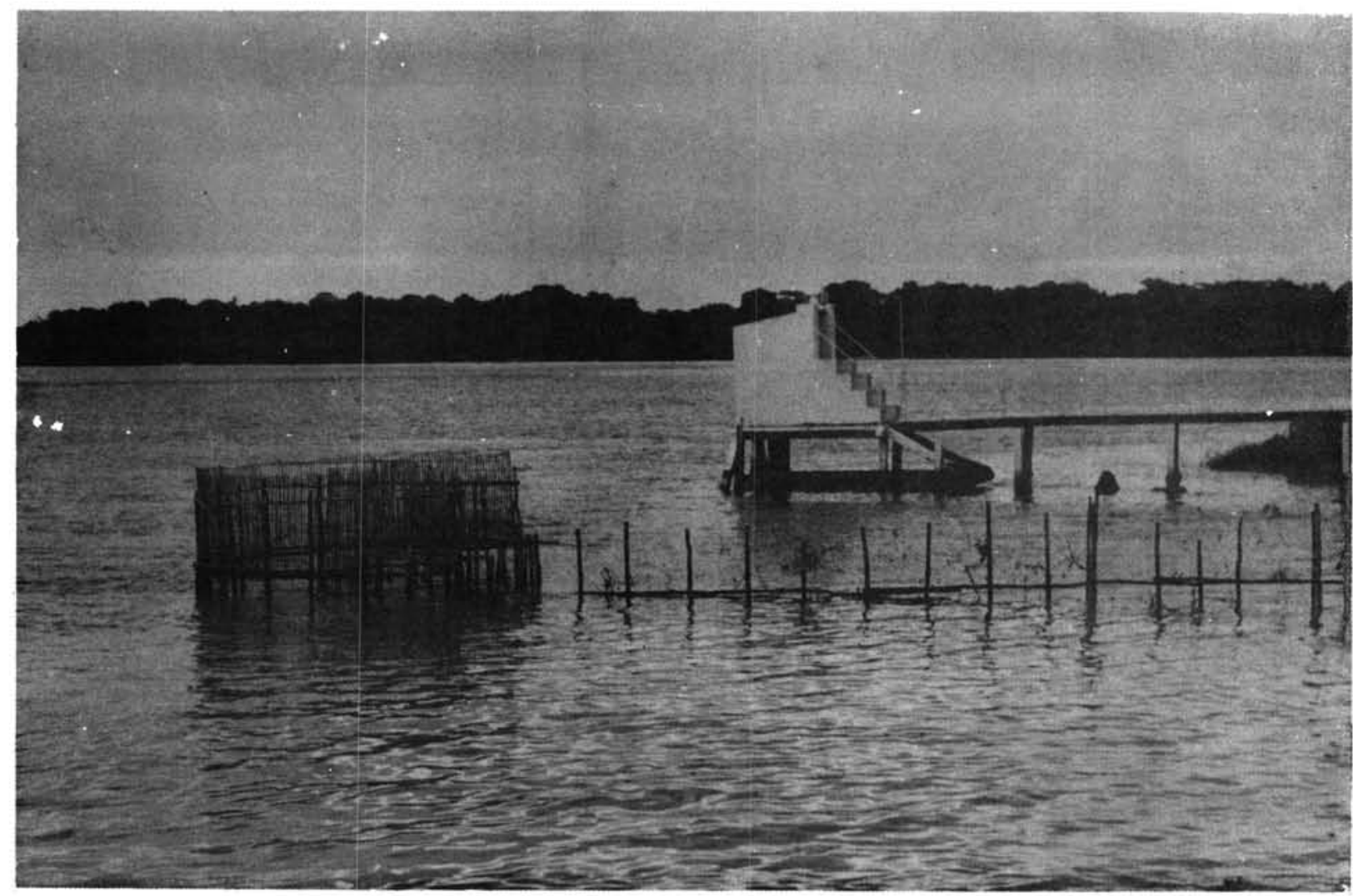

Fig. 1 - Cerco fixo e ponto de localização do marégrafo, do termômetro e das determinações de salinidade utilizados no presente estudo. 


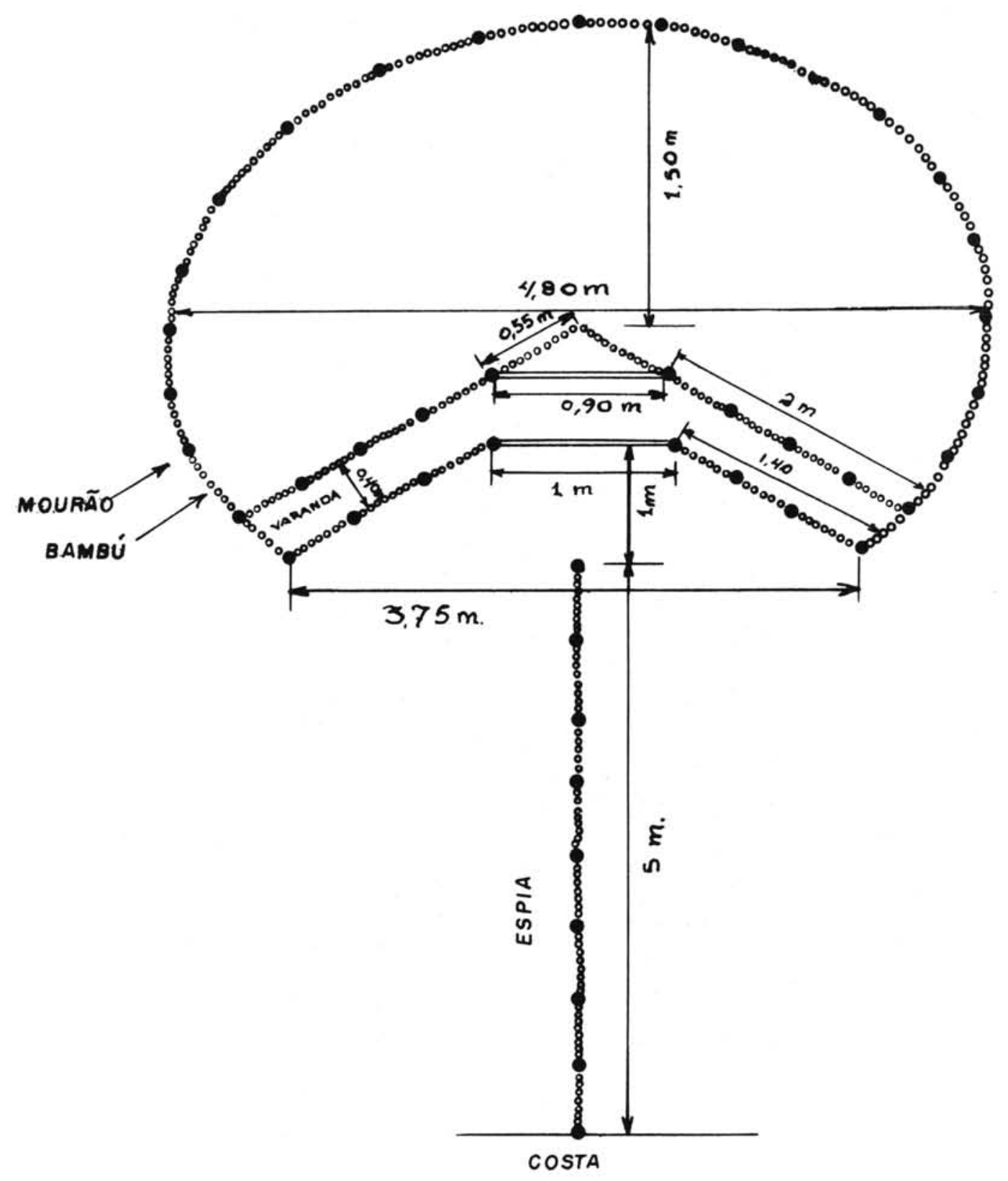

Fig. 2 - Planta do cerco fixo. 


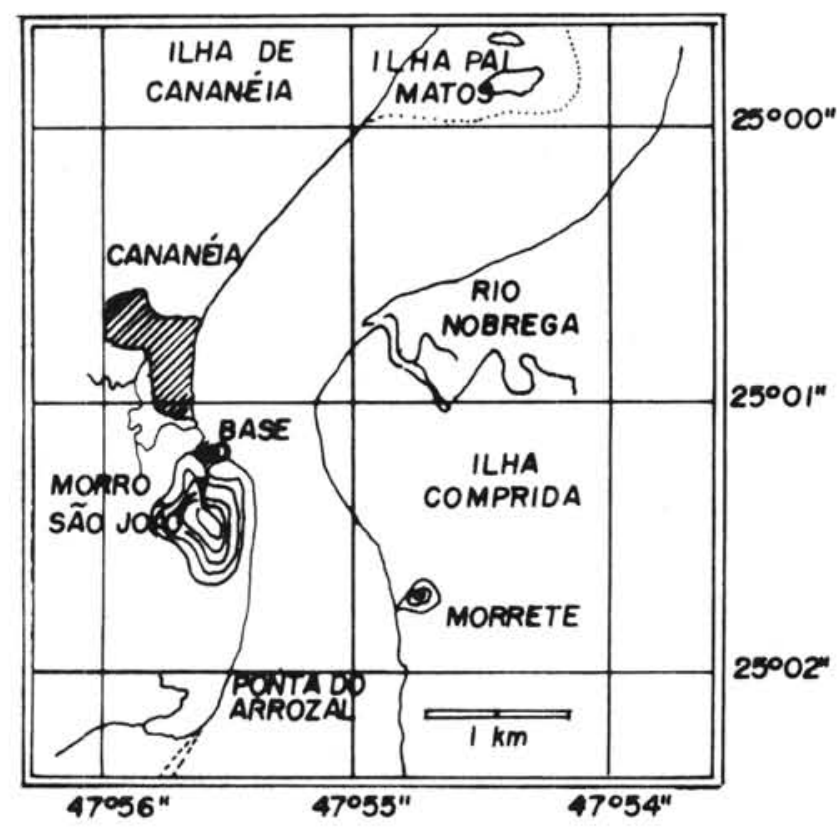

Fig. 3 - Região lagunar de Cananēia.

Durante quatro anos de estudo foram efetuadas verificações semanais quanto às espécies de peixes coletados, sendo que nos primeiros três anos foram anotados comprimento e peso total de quatro espēcies: carapeba (Diopterus rhombeus), caratinga (Diapterus brasiliensis), sargo-de-dentes (Archosargus aries) e taînha (Mugil cephalus).

Um estudo mais detalhado foi efetuado durante os 11 meses do ültimo ano de observações, sendo obtidos dados sobre comprimento, peso, sexo e grau de maturidade sexual de todos os exemplares coletados, abrangendo um total de 32 espēcies de peixes.

Para a obtenção dos dados biométricos consideram-se:

a) Comprimento total (Lt, distância entre o focinho e a extremidade da nadadeira caudal): com aproximação de $0,1 \mathrm{~cm}$; 
Bolm Inst. oceanogr., S Paulo, 25, 1976

b) Peso total (Wt): com aproximação de $0,1 \mathrm{~g}$;

c) Maturidade sexual: Escala de Heincke e Meier descrita por Meissner (1933); sendo que, em alguns casos, os 8 estādios originalmente propostos por estes autores foram grupados em imaturo (I a III), maduro (IV a VII) e desovado (VIII).

DETERMINAÇÕES METEOROLÓGICAS E HIDROGRÅFICAS -

Durante 1967, concomitantemente às observações biomētricas, foram efetuadas determinações da temperatura e salinidade da āgua da superfície, marē, precipitação pluviomētrica, temperatura do ar e condições atmosfēricas. Em dias de maior precipitação pluviométrica a salinidade foi determinada a diferentes profundidades.

A salinidade foi determinada por meio de anālises titulométricas (nitrato de prata) efetuadas no Departamento de Oceanografia Física do Instituto Oceanogrāfico da USP, bem como, em alguns casos, por meio de salinômetro (GEMWARE SALINITY TESTING SET, M.F.G. Co. New York, N.Y. USA). Os níveis de maré foram anotados a partir das variações verificadas no maregrafo instalado na Base Sul. Nesta dependência foram também observadas diariamente, às 09:00, 15:00 e 21:00 horas, os dados referentes à precipitação pluviométrica, temperatura do ar e da água. A temperatura da água foi determinada por meio de hidrotermógrafo "mercury stell" com bulbo remoto a um metro abaixo do níve1 da mesma.

\section{RESULTADOS E DISCUSSÃO}

Foi observado que o cerco fixo propiciou durante 1964 a 1967 a captura de 32 espécies de peixes (Tab. I), sendo que a carapeba e a taínha foram respectivamente, a primeira e a segunda em produção por peso (Tabs I-II). 
TABELA I - Espécies capturadas durante 1964-67

\begin{tabular}{|c|c|c|}
\hline NOME COMUM & ESPECIE & FAMILIA \\
\hline $\begin{array}{r}\text { Acarā } \\
\text { Badejo } \\
\text { Bagre } \\
\text { Baiacú } \\
\text { Caranha } \\
\text { Carapeba } \\
\text { Carapicú } \\
\text { Carapitanga } \\
\text { Caratinga } \\
\text { Corcoroca } \\
\text { Corvina } \\
\text { Galo Penacho } \\
\text { Linguado } \\
\text { Mamangava } \\
\text { Marimba } \\
\text { Mero } \\
\text { Miraguaia } \\
\text { Morcego } \\
\text { Pampo } \\
\text { Parati } \\
\text { Parú } \\
\text { Xarelete }\end{array}$ & 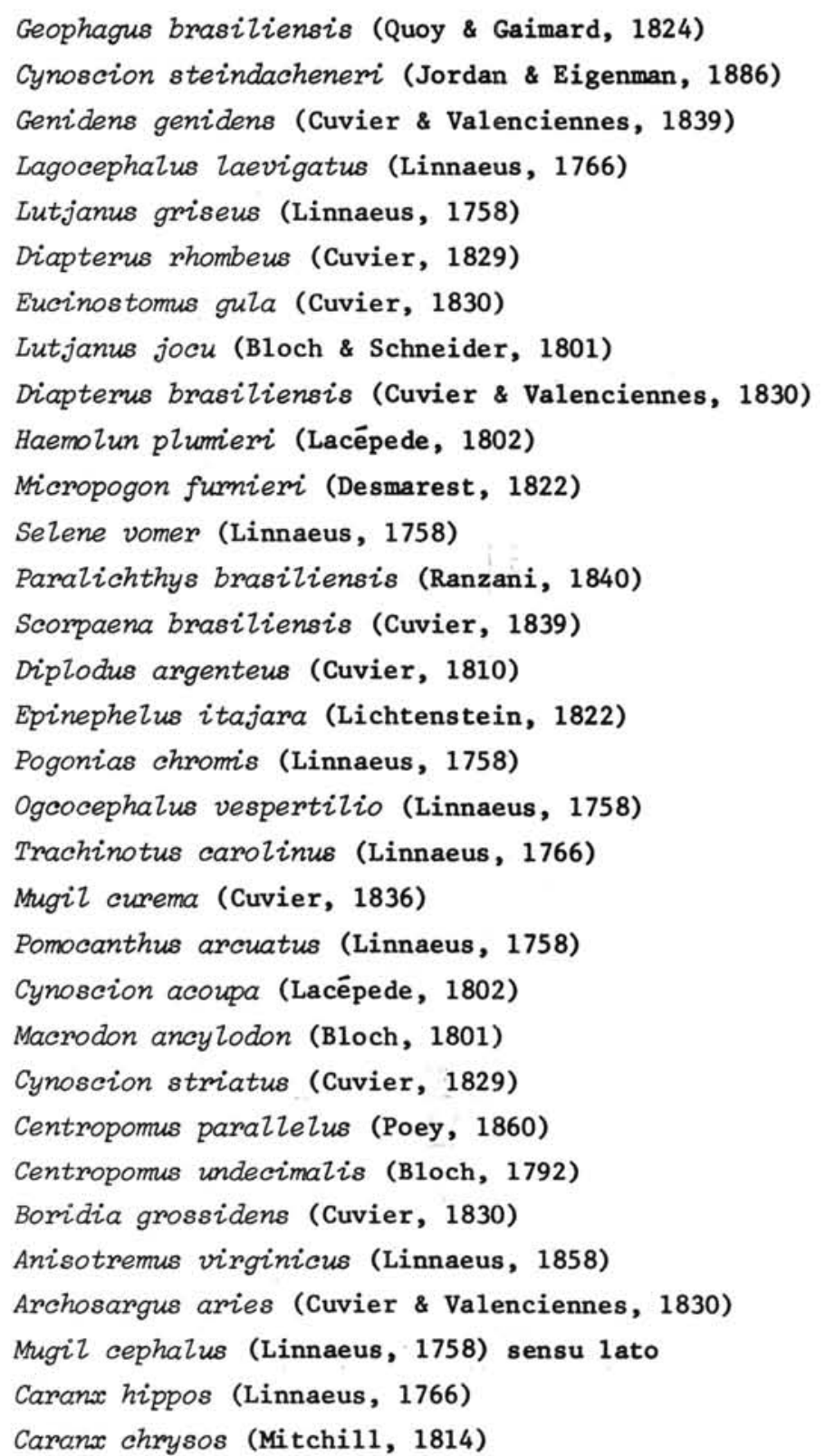 & $\begin{array}{l}\text { Cichlidae } \\
\text { Sciaenidae } \\
\text { Ariidae } \\
\text { Tetraodontidae } \\
\text { Lutjanidae } \\
\text { Gerridae } \\
\text { Gerridae } \\
\text { Lutjanidae } \\
\text { Gerridae } \\
\text { Pomadasyidae } \\
\text { Sciaenidae } \\
\text { Carangidae } \\
\text { Bothidae } \\
\text { Scorpaenidae } \\
\text { Sparidae } \\
\text { Serranidae } \\
\text { Sciaenidae } \\
\text { Ogcocephalidae } \\
\text { Carangidae } \\
\text { Mugilidae } \\
\text { Chaetodontidae } \\
\text { Sciaenidae } \\
\text { Sciaenidae } \\
\text { Sciaenidae } \\
\text { Centropomidae } \\
\text { Centropomidae } \\
\text { Pomadasyidae } \\
\text { Pomadasyidae } \\
\text { Sparidae } \\
\text { Mugilidae } \\
\text { Carangidae } \\
\text { Carangidae }\end{array}$ \\
\hline
\end{tabular}


Bolm Inst. oceanogr., S Paulo, 25, 1976

TABELA II - Capturas de carapeba, taínha, sargo-de-dentes e caratinga efetuadas durante 1964-67

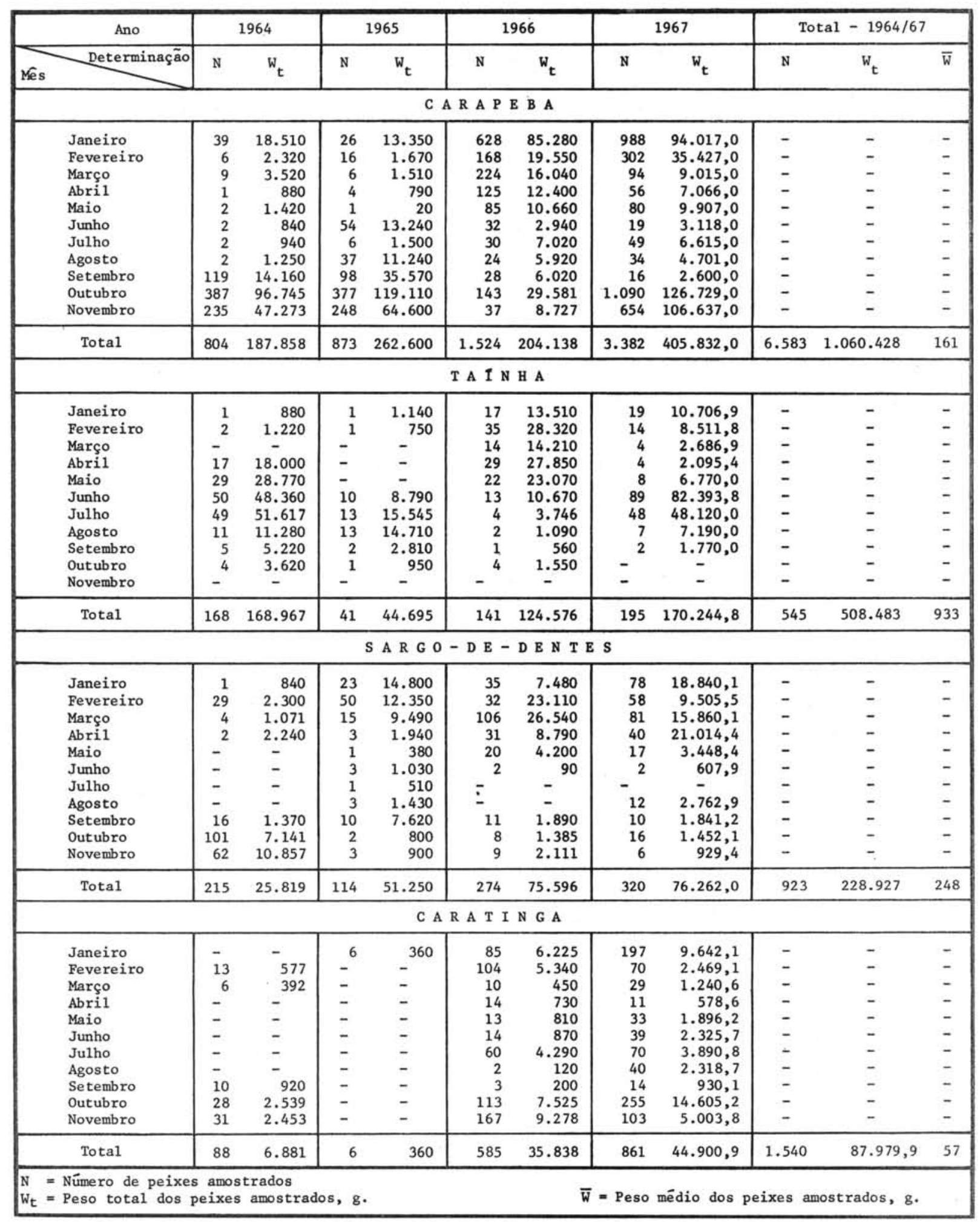


Analisando-se as capturas efetuadas em 1967 verifica-se que as espécies que mais contribuíram em peso, excetuando-se o mero cuja ocorrência foi ocasional, foram em ordem decrescente: carapeba, taínha, sargo-de-dentes, robalão, caratinga, paratī, robalo, parū e corcoroca (Tab. III). Dentro de uma produção total de aproximadamente $902 \mathrm{Kg}$ de peixes, perfazendo um total de 5.345 exemplares, estas nove espécies contribuíram com 5.177 espēcimens e $846 \mathrm{Kg}$ enquanto as demais 23 concorreram com 168 exemplares e $56 \mathrm{Kg}$. No presente trabalho as nove espécies mais numerosas são consideradas como integrantes da pesca principal, enquanto as demais 23 como pesca complementar (Tabs IV-V).

Observa-se que a produção de carapeba e taĩnha tem influência predominante sobre a produção total do cerco, sendo para tanto computada a produção das nove espécies principais (Fig. 4). Estas duas espécies influenciam a produção do cerco fixo, em épocas diferentes, sendo a carapeba, no período de setembro a março e a taínha de maio a agosto. A carapeba foi capturada em número e peso total bastante superior ao da taínha, com esta ūltima superando-a em alguns meses da sua safra, isto è de maio a agosto (Tabs III-IV). Estas espécies influenciam a produção total em épocas diferentes, tendo assim safras bem distintas.

Comparando o peso médio das taínhas e das carapebas capturadas em 1964-67, respectivamente 933 e 161 gramas (Tab. II), verifica-se que a taînha contribui com exemplares de elevado peso médio o que aliado ao seu valor comercial concorre para que a mesma seja visada pelos pescadores. Observou-se também que o período em que a taínha apresentou maior produção no presente estudo coincide com a época em que o cerco fixo è localmente utilizado na pesca comercial, isto é de abril a agosto. Por outro lado, a produção de elevada quantidade de carapeba com baixo peso médio fora da safra da taînha poderā concorrer como meio de subsistência para os pescadores e população local. Dessa maneira, a interpretação dos resultados obtidos no presente estudo poderá sugerir a utilização local do cerco fixo em capturas comerciais no período de maio a agosto e de subsistência entre setembro a março, visando principalmente a taínha no primeiro e a carapeba no segundo. 
TABELA III - Observação da pesca de cerco fixo durante 1967 *

\begin{tabular}{|c|c|c|c|c|c|c|c|c|c|c|c|c|c|}
\hline Meses & Jan. & Fev. & Mar. & Abr. & Mai. & Jun. & Jul. & Ago. & Set. & Out. & Nov. & Total & Total \\
\hline Espécies & 13 & 11 & 14 & 10 & 14 & 8 & 12 & 11 & 13 & 10 & 12 & 128 & \\
\hline Acarā & 1 & - & 1 & 2 & 1 & 1 & - & - & - & - & - & 6 & 558,8 \\
\hline Badejo & 1 & 1 & 1 & - & - & - & - & - & - & - & - & 3 & $1.300,0$ \\
\hline Bagre & - & - & - & - & 1 & - & 2 & - & - & - & 2 & 5 & $1.147,3$ \\
\hline Baiacú & 1 & 3 & - & - & - & - & 5 & 4 & - & 11 & 6 & 30 & $5.576,8$ \\
\hline Caranha & - & - & - & 2 & - & - & - & - & - & - & - & 2 & 696,6 \\
\hline Carapeba & 988 & 302 & 94 & 56 & 80 & 19 & 49 & 34 & 16 & 1.090 & 654 & 3.382 & $405.832,0$ \\
\hline Carapitanga & - & - & - & 1 & - & - & - & - & - & - & - & 1 & 178,5 \\
\hline Caratinga & 197 & 70 & 29 & 11 & 33 & 39 & 70 & 40 & 14 & 255 & 103 & 861 & $44.900,9$ \\
\hline Corcoroca & 4 & - & 38 & 9 & 5 & 7 & 1 & - & - & - & - & 64 & $7.144,6$ \\
\hline Corvina & - & - & - & 3 & 1 & - & 1 & - & - & - & 1 & 6 & $2.329,5$ \\
\hline Carapicu & - & - & - & - & - & - & 3 & 2 & - & 1 & 1 & 7 & 702,1 \\
\hline Galo penacho & 5 & 2 & - & - & - & - & - & - & - & - & - & 7 & 876,9 \\
\hline Linguado & - & - & 1 & - & 1 & - & - & - & - & - & - & 2 & $2.376,0$ \\
\hline Mamangava & - & - & 1 & - & - & - & - & - & 1 & - & - & 2 & 418,0 \\
\hline Marimba & - & 1 & - & - & - & - & - & - & - & - & - & 1 & 377,0 \\
\hline Mero & 2 & - & - & - & - & - & - & - & - & - & - & 2 & $16.100,0$ \\
\hline Miraguaia & - & 1 & - & 1 & 2 & - & - & 2 & - & 3 & - & 9 & $5.330,6$ \\
\hline Morcego & 3 & - & - & - & - & 1 & 1 & - & - & - & - & 5 & $1.278,1$ \\
\hline Pampano & - & 1 & - & - & - & - & - & - & - & - & - & 1 & 26,5 \\
\hline Parati & 12 & 1 & 5 & 6 & 10 & 19 & 10 & 17 & 5 & 31 & 16 & 132 & $43.627,8$ \\
\hline Parú & 28 & 37 & 12 & 15 & 2 & - & - & 2 & - & 3 & 5 & 104 & $14.397,6$ \\
\hline Pescada-jaguara & 2 & 1 & 4 & - & - & - & - & - & 1 & 1 & - & 9 & $6.173,9$ \\
\hline Pescada-olhuda & 1 & - & - & - & 1 & - & - & - & 1 & - & - & 3 & $1.390,0$ \\
\hline Pescada-foguete & - & - & - & - & - & - & - & - & - & 1 & - & 1 & 940,0 \\
\hline Robalão & 13 & 3 & 14 & 11 & 11 & 3 & 1 & 1 & - & 1 & - & 58 & $64.427,2$ \\
\hline Robalo & 10 & 5 & 9 & 3 & 6 & - & - & 1 & 1 & 11 & 15 & 61 & $19.253,3$ \\
\hline Saguã & 6 & 5 & - & 1 & - & 1 & - & - & - & 6 & 1 & 20 & $2.638,4$ \\
\hline Salema & 2 & 1 & 3 & - & 2 & - & 1 & - & 1 & - & - & 10 & $1.720,5$ \\
\hline Sargo-de-dentes & 78 & 58 & 81 & 40 & 17 & 2 & - & 12 & 10 & 16 & 6 & 320 & $76.262,0$ \\
\hline Taínha & 19 & 14 & 4 & 4 & 8 & 89 & 48 & 7 & 2 & - & - & 195 & $170.244,8$ \\
\hline Xarelete & 12 & - & - & 1 & - & - & 2 & - & - & 17 & 1 & 33 & $3.936,7$ \\
\hline Xarēu & - & - & - & 2 & 1 & - & - & - & - & - & - & 3 & 219,7 \\
\hline Total & 1.385 & 506 & 297 & 166 & 183 & 182 & 194 & 122 & 52 & 1.447 & 811 & 5.345 & $902.383,1$ \\
\hline
\end{tabular}




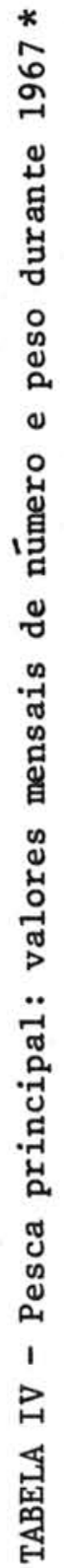

\begin{tabular}{|c|c|c|c|c|c|c|c|c|c|c|c|}
\hline ذّ & 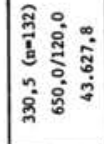 & 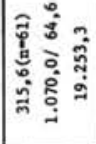 & 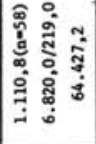 & 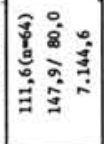 & 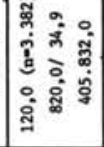 & 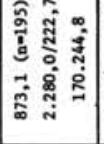 & 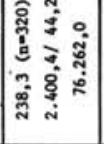 & 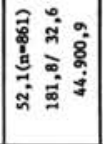 & 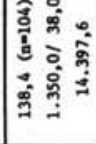 & 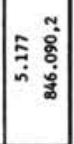 & \\
\hline$\frac{8}{10}$ & 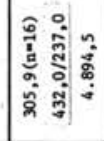 & 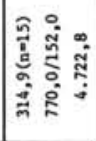 & l. & ( . ' & 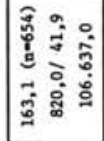 & $\therefore$ & 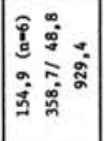 & 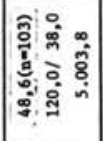 & 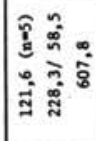 & 天 & \\
\hline 竞 & 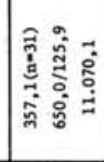 & 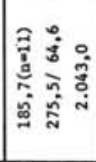 & 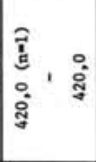 & & 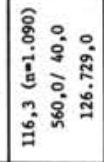 & & 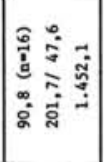 & 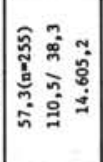 & 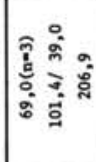 & 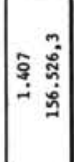 & \\
\hline 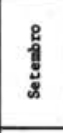 & 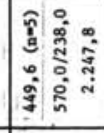 & 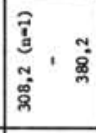 & $\because$ & $\cdots$ & 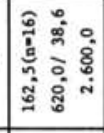 & 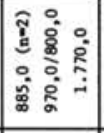 & 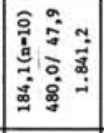 & 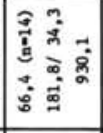 & $\ldots$ & 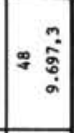 & \\
\hline 幂 & 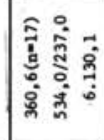 & 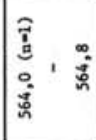 & 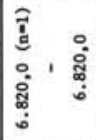 & & 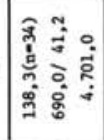 & 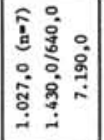 & 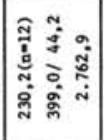 & 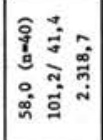 & 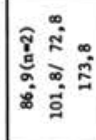 & 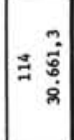 & \\
\hline : & 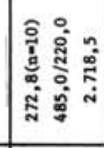 & ' & 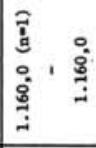 & 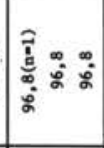 & 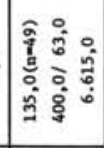 & 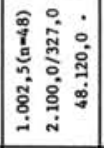 & $\cdots$ & 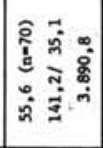 & & 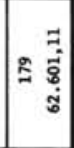 & \\
\hline 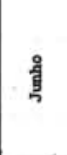 & 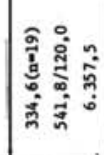 & ' ' & 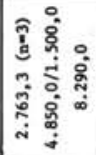 & 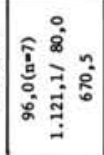 & 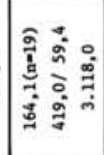 & 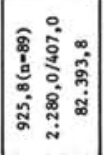 & 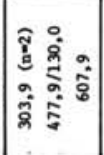 & 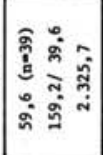 & & 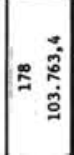 & \\
\hline$\frac{8}{1}$ & 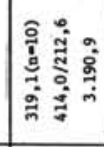 & 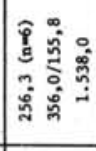 & 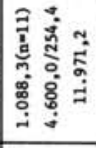 & 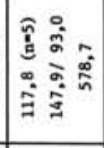 & 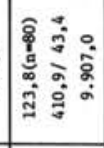 & 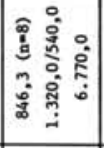 & 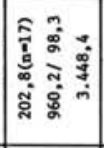 & 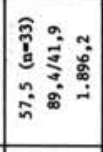 & 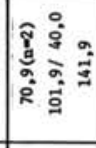 & 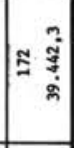 & \\
\hline 泀 & 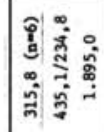 & 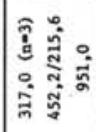 & 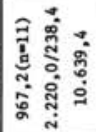 & 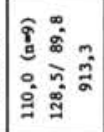 & 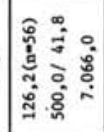 & 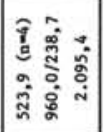 & 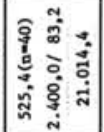 & 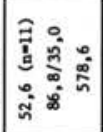 & 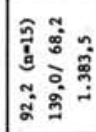 & 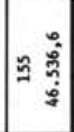 & \\
\hline$\check{1}$ & 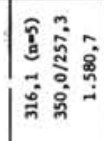 & 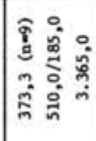 & 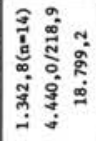 & 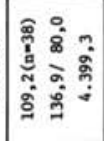 & 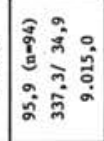 & 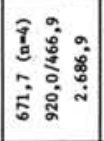 & 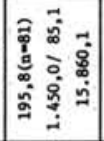 & 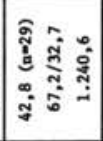 & 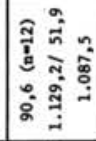 & 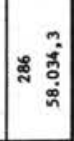 & \\
\hline & 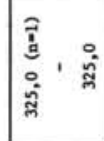 & 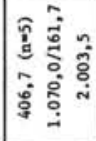 & 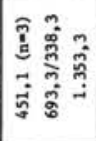 & & 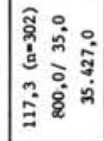 & 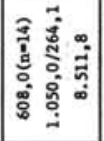 & 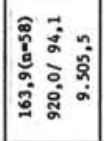 & 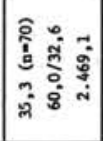 & 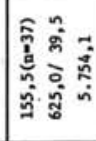 & ‡: & \\
\hline 星 & 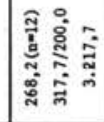 & 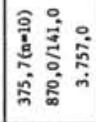 & 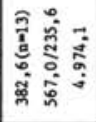 & 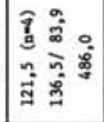 & 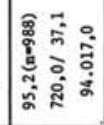 & 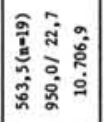 & 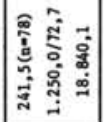 & 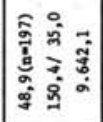 & 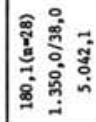 & 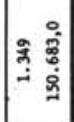 & \\
\hline i & $1 \times=$ & $1 \times$ & $\begin{array}{l}x> \\
1 x=\end{array}$ & $1 \times=$ & $1 x=$ & $x>$ & $\begin{array}{ll}x & \\
1 x & =\end{array}$ & $\begin{array}{l}x \\
10\end{array}$ & $\begin{array}{l}x> \\
1 x\end{array}$ & 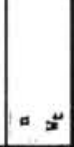 & \\
\hline 营: & $\ddot{\ddot{u}}$ & 高 & $\begin{array}{l} \\
\end{array}$ & \begin{tabular}{|l|l|} 
\\
\\
\\
8
\end{tabular} & : & $\mathrm{d}$ & 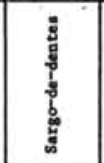 & 蛋 & 眔 & 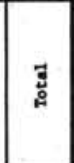 & \\
\hline
\end{tabular}




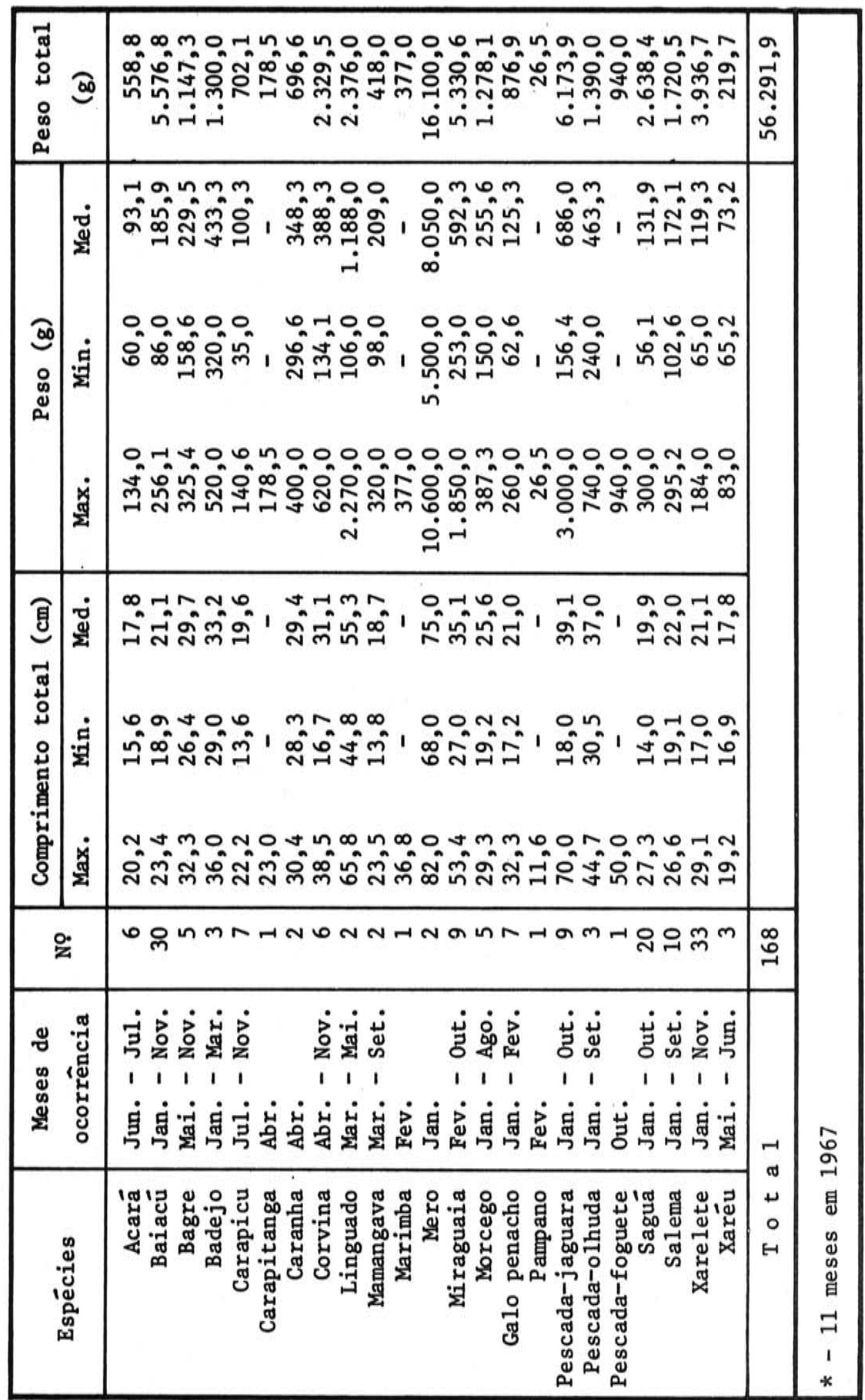




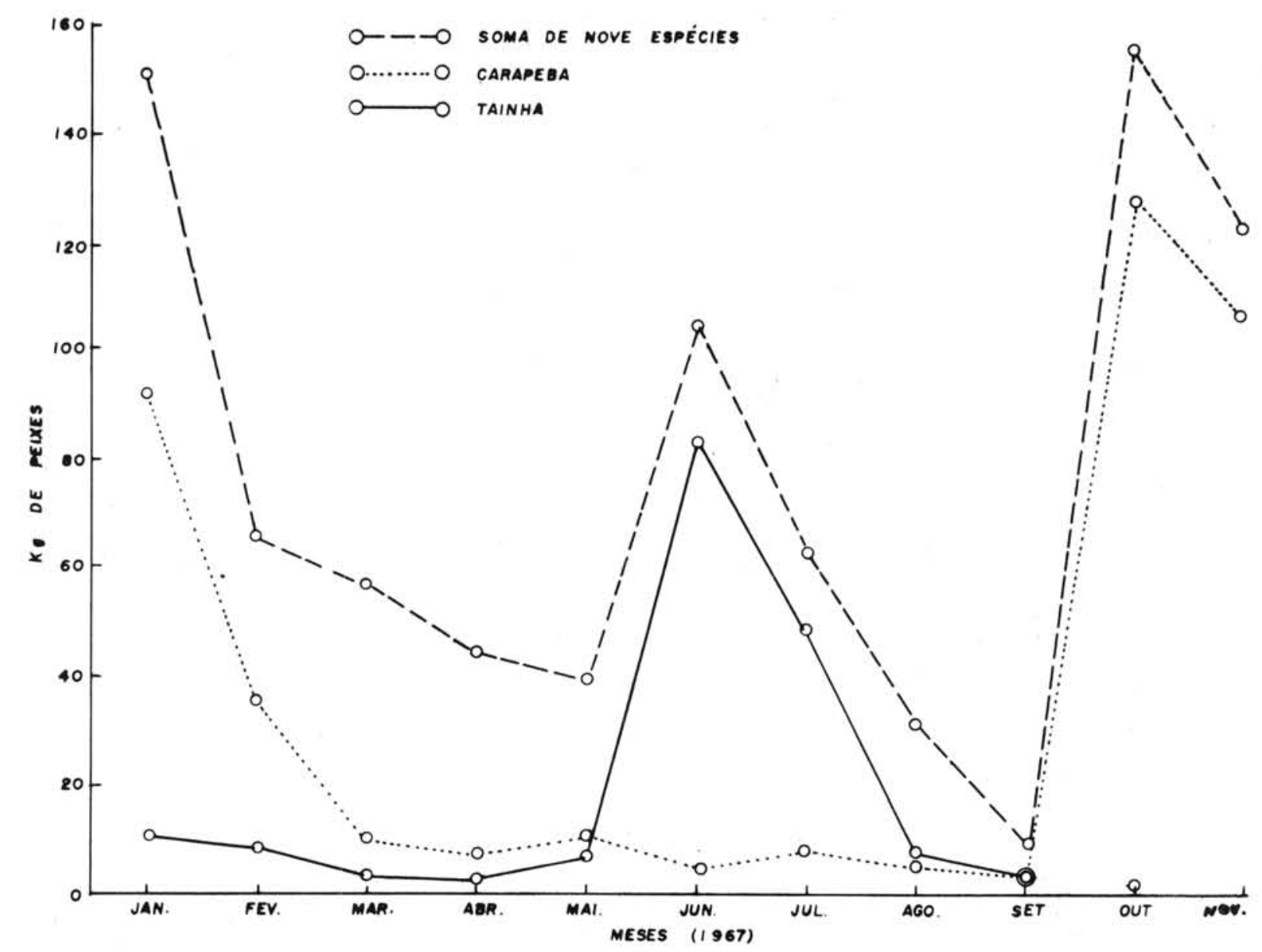

Fig. 4 - Relações entre os pesos da carapeba, da taínha e dos integrantes da pesca principal durante 1967.

0 aparelho de captura aqui considerado, aprisionou durante 1967, exemplares com comprimentos totais de $93,0 \mathrm{~cm}$, robalão, e $10,4 \mathrm{~cm}$, parü. Os integrantes das espēcies carapeba, taínha, sargo-de-dentes, parū, paratí, robalo e robalão apresentaram diferenças entre os exemplares dos dois sexos, sendo as fêmeas maiores que os machos. Esta diferença de tamanho não ē evidente nas espécies caratinga e corcoroca (Fig. 5).

Nas espēcies carapeba, caratinga, taỉnha e robalão foram capturados maior nümero de machos do que fêmeas, enquanto nas espécies sargo-de-dentes, paratí, robalo e corcoroca foram coletados maior número de fêmeas do que machos (Tab. IV). 

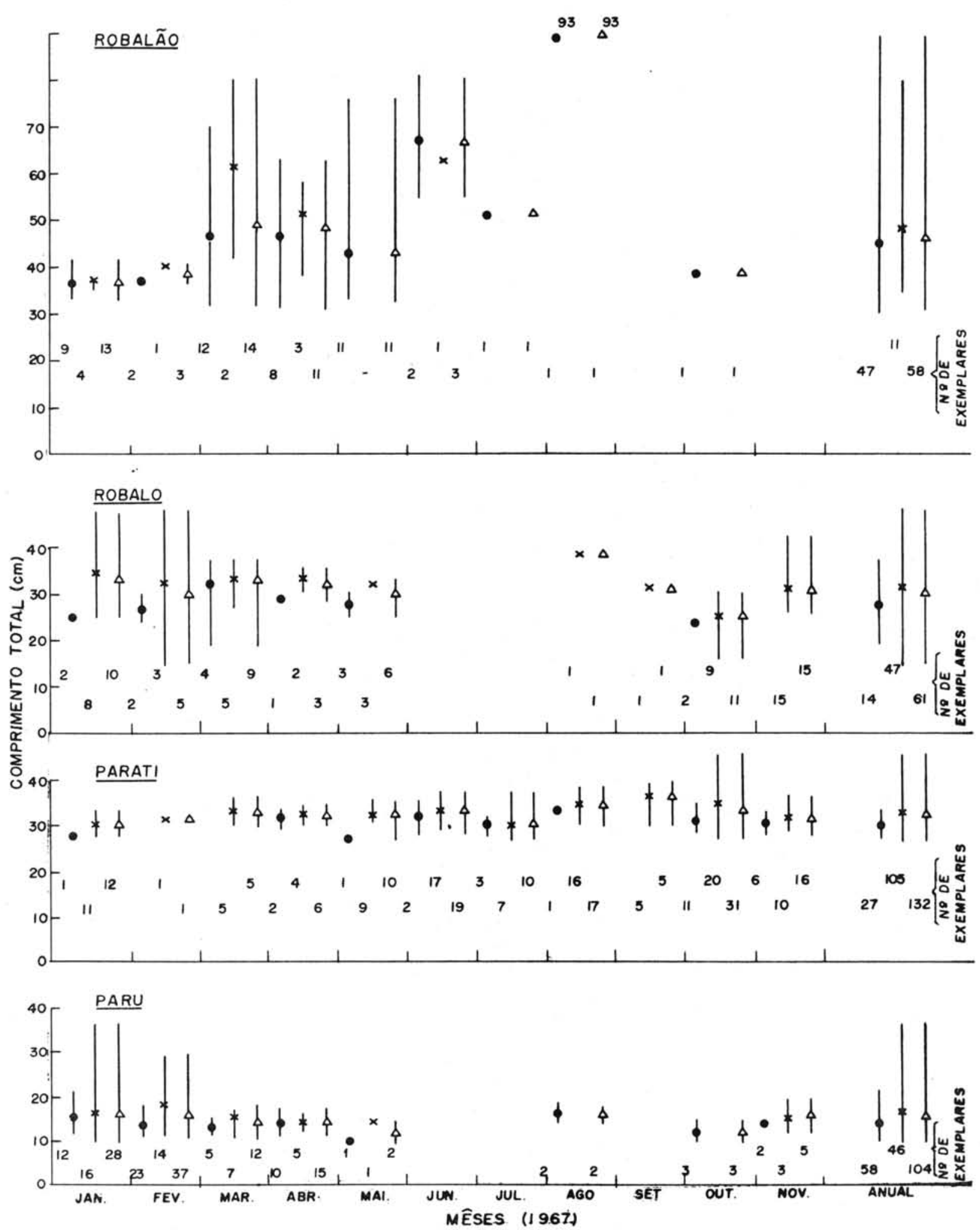

Fig. 5 - Pesca principal: índices mensais de comprimento mëdio por espëcie em 1967. 


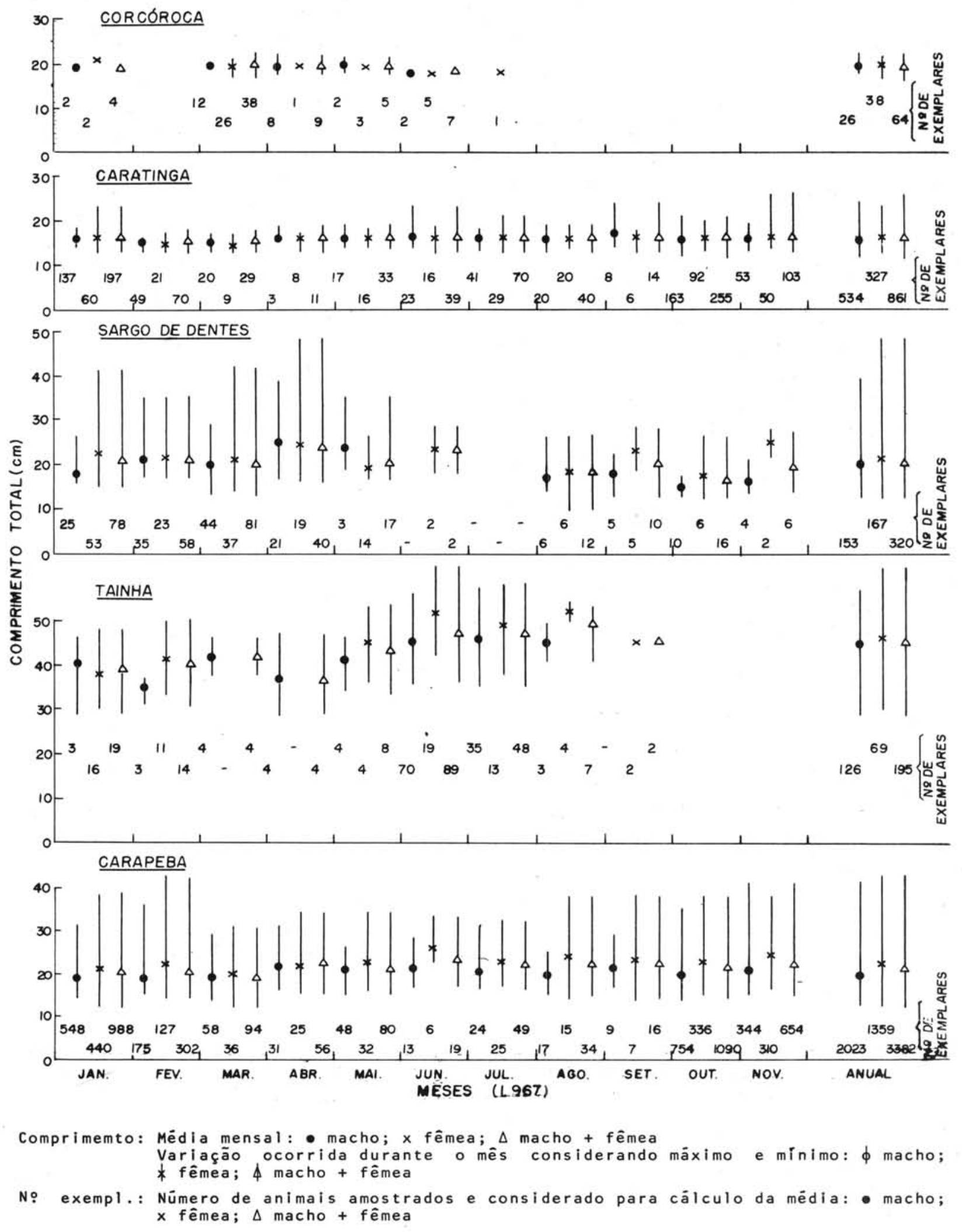


Bolm Inst. oceanogr., S Paulo, 25, 1976

Verificou-se que entre as nove espēcies consideradas para um estudo mais detalhado em 1967, somente a taínha apresentou ocorrência de espēcimens maduros em época bem delimitada do ano. Esta época estende-se por cinco meses, sendo constatada a presença de machos maduros de abril a agosto, e de fêmeas maduras de maio a agosto (Tabs VI-VII). Essa observação sugere a possibilidade de que a desova da taínha ocorra neste período.

Entre as outras espécies foi observado que o parü, o paratí, o robalo e o sargo-de-dentes apresentam exemplares maduros durante $11,10,10$ e 11 meses, respectivamente, durante o ano de 1967. Não foram observados no período estudado, exemplares maduros das espécies robalão e corcoroca apesar de terem sido capturados exemplares de grande porte, atingindo $93,0 \mathrm{~cm} \mathrm{e}$ $22,2 \mathrm{~cm}$ de comprimento, respectivamente.

As indicações dos tamanhos médios em que as espécies iniciam sua maturação sexual ( $\mathrm{Tab}$. VIII) mostram que os machos de taínha maturam com $33 \mathrm{~cm}$ e as fêmeas com $38 \mathrm{~cm}$. As demais espēcies analisadas apresentam-se maduras respectivamente para machos e fêmeas, como segue: carapeba, 13 e $12 \mathrm{~cm}$; caratinga, 12 e $13 \mathrm{~cm}$; paratí, 28 e $30 \mathrm{~cm}$; parū, 11 e $13 \mathrm{~cm}$; robalo, 24 e $16 \mathrm{~cm}$; e $18 \mathrm{~cm}$ para as fêmeas de sargo-de-dentes, não tendo sido considerados os machos por ter sido capturado somente um macho maduro.

Observa-se que o período de maior abundância de taínha coincide com a ocorrência de exemplares maduros e comparando-se estas indicações como os dados de temperatura da águe (Fig. 6) verifica-se que nessa época do ano a temperatura média mensal ē de $21,1^{\circ} \mathrm{C}$ em junho e $19,8^{\circ} \mathrm{C}$ em julho. 0 decrēscimo da temperatura da āgua coincide com um aumento de produção de taínha, enquanto a carapeba ocorre em época de temperatura mais elevada, isto é, com média mensal igual a $26,5^{\circ} \mathrm{C}$, em janeiro e aumento de novo em outubro.

Besnard (1950b) na citação:

"grandes concentrações de Mugilídeos (taỉnha e paratî) os quais, durante o período das migrações procuram águas salobras ... do Mar Pequeno, nos mares de Cananéia e Cubatão" - relaciona a presença destes peixes com a mistura das āguas oceânicas que entram na região de Cananéia e as provenientes da drenagem dos rios. Pelos dados do atual trabalho, verifica-se que 
nas épocas de maior ocorrência de taínhas no cerco fixo, constataram-se elevados valores da salinidade da āgua, atingindo um máximo em junho. Machado (1950) também observou valor elevado de salinidade no mar de Cananēia neste mês $(22,09 \%)$ ocorrendo em plena estação hibernal, época em que a ausência de precipitação diminui consideravelmente a contribuição em àgua doce dos rios.

A localização do cerco fixo junto à Base Sul, na entrada do mar de Cananéia, é bastante interessante em relação ao estudo da influência da salinidade e nível de marē sobre os peixes capturados por esse aparelho, influência essa que se faz sentir sobre os mesmos, nos seus deslocamentos pela laguna e, por conseguinte na sua captura pela armadilha. Kato (1966a) estudando o sistema hidrogrāfico desta região constatou que a água oceânica penetra na região lagunar durante a marē alta, através da barra de Cananēia, sendo que a maior parte dessa água toma direção oeste, pela baía de Trapandē, represando a região lagunar para o Norte, enquanto uma quantidade menor entra pela parte leste, pelo chamado mar de Cananéia, no qual é impedida pela exiguidade da passagem. Na parte interna da região lagunar, o aumento do nível das águas depende, aparentemente de um acūmulo de água dos tributārios, causados pelas ondas da maré. A queda do nível do mar durante a marē baixa, puxa para fora as āguas da região lagunar e comumente observa-se uma grande velocidade do fluxo da água, que sai através da estreita passagem do mar de Cananéia. o cerco fixo estā localizado justamente do lado interno dessa passagem.

Pelos dados da Tabela IX verifica-se a influência que fortes chuvas e o conseqüente aumento da vazão fluvial, acarretam na região do cerco. Em épocas de intensa precipitação a salinidade cai a valores baixos, por exemplo no dia 13 de abril de 1966, quando na superfície, chegou a 4,5\% No dia seguinte, apōs três dias de enchentes, foi capturado no cerco fixo um exemplar de traíra (Hoplias malabaricus - Erythrinidae) espécie esta, característica de água doce. Este foi o primeiro registro de uma traíra em 14 anos nesta região lagunar. Esta observação concorda com o apresentado por Besnard $(1950 a)$ com respeito a influência de grandes cheias do rio Ribeira de Iguape nas āguas da região lagunar. Esse autor cita que: 
TABELA VI - Pesca principal: distribuição de machos e fêmeas de acordo com o grau de maturidade sexual durante 1967

\begin{tabular}{|c|c|c|c|c|c|c|c|c|c|c|c|c|c|c|c|c|c|c|}
\hline \multirow{3}{*}{ Mes } & \multicolumn{8}{|c|}{ MACHOS } & \multicolumn{8}{|c|}{ FEMEAS } & \multicolumn{2}{|c|}{ MACHOS + FEMEAS } \\
\hline & \multicolumn{8}{|c|}{ Grau de Maturidade } & \multicolumn{8}{|c|}{ Grau de Maturidade } & \multirow{2}{*}{\multicolumn{2}{|c|}{ Ne total $M / F(z)$}} \\
\hline & I & II & III & IV & $v$ & VI & VII & No & I & II & III & IV & $\mathrm{v}$ & VI & VII & No & & \\
\hline \multicolumn{19}{|c|}{$C A R A P E B A$} \\
\hline Janeiro & 9 & 49 & 1 & - & - & 487 & 2 & 548 & 20 & 10 & 1 & - & - & 407 & 2 & 440 & 988 & $55,5 / 44,5$ \\
\hline Fevereiro & 3 & 6 & 3 & - & - & 163 & - & 175 & 18 & 18 & 6 & - & - & 85 & - & 127 & 302 & $57,9 / 42,1$ \\
\hline Março & 2 & 1 & 1 & - & 3 & 51 & - & 58 & 4 & 17 & 7 & - & 1 & 7 & - & 36 & 94 & $61,7 / 38,3$ \\
\hline Abril & 1 & 1 & - & - & - & 29 & - & 31 & 1 & 7 & 5 & - & - & 12 & - & 25 & 56 & $55,4 / 44,6$ \\
\hline Maio & - & 1 & 2 & - & - & 45 & - & 48 & 1 & 8 & 12 & - & - & 11 & - & 32 & 80 & $60,0 / 40,0$ \\
\hline Junho & 1 & 2 & 1 & - & 1 & 8 & - & 13 & - & 1 & 3 & 1 & 1 & - & - & 6 & 19 & $68,4 / 31,6$ \\
\hline Julho & 2 & 3 & 5 & - & - & 14 & - & 24 & - & 3 & 6 & - & - & 16 & - & 25 & 49 & $49,0 / 51,0$ \\
\hline Agosto & 4 & 5 & 8 & 2 & - & - & - & 19 & - & 2 & 8 & 2 & 1 & 2 & - & 15 & 34 & $55,9 / 44,1$ \\
\hline Setembro & - & 1 & - & - & 3 & 5 & - & 9 & - & 2 & 1 & 1 & 3 & - & - & 7 & 16 & $56,2 / 43,8$ \\
\hline Outubro & - & - & - & 1 & 3 & 749 & 1 & 754 & - & 3 & 3 & - & 4 & 323 & 3 & 336 & 1.090 & $69,2 / 30,8$ \\
\hline Total & 22 & 69 & 21 & 4 & 12 & 1.892 & 3 & 2.023 & 44 & 72 & 52 & 4 & 10 & 1.161 & 16 & 1.359 & 3.382 & $59,8 / 40,2$ \\
\hline \multicolumn{19}{|c|}{ T A I N н A } \\
\hline Janeiro & 1 & 2 & - & - & - & - & - & 3 & 11 & 2 & 3 & - & - & - & - & 16 & 19 & $15,8 / 84,2$ \\
\hline Fevereiro & 3 & - & - & - & - & - & - & 3 & 6 & 5 & - & - & - & - & - & 11 & 14 & $21,4 / 78,6$ \\
\hline Março & - & 1 & 3 & - & - & - & - & 4 & - & - & - & - & - & - & - & - & 4 & $100 /=$ \\
\hline Abri1 & 1 & - & - & - & - & 3 & - & 4 & - & - & - & - & - & - & - & - & 4 & $100 /-$ \\
\hline Maio & - & - & 1 & - & - & 3 & - & 4 & - & 1 & 1 & 2 & - & - & - & 4 & 8 & $50,0 / 50,0$ \\
\hline Junho & - & - & 2 & 1 & 3 & 62 & 2 & 70 & - & - & 1 & - & 1 & 9 & 8 & 19 & 89 & $78,7 / 21,3$ \\
\hline Julho & - & 1 & - & - & 3 & 30 & 1 & 35 & - & - & - & 1 & 5 & 4 & 3 & 13 & 48 & $72,9 / 27,1$ \\
\hline Agosto & - & - & - & - & - & 3 & - & 3 & - & - & - & - & - & 1 & 3 & 4 & 7 & $42,9 / 57,1$ \\
\hline Setembro & - & - & - & - & - & - & - & - & - & - & 2 & - & - & - & - & 2 & 2 & -1100 \\
\hline Total & 5 & 4 & 6 & 1 & 6 & 101 & 3 & 126 & 17 & 8 & 7 & 3 & 6 & 14 & 14 & 69 & 195 & $64,6 / 35,4$ \\
\hline \multicolumn{19}{|c|}{$S A R G O-D E-D E N T E S$} \\
\hline Janeiro & 25 & - & - & - & - & - & - & 25 & 25 & 15 & 5 & - & - & 8 & - & 53 & 78 & $32,1 / 67,9$ \\
\hline Pevereiro & 30 & 4 & 1 & - & - & - & - & 35 & 6 & 13 & 4 & - & - & - & - & 23 & 58 & $60,3 / 39,7$ \\
\hline Março & 34 & 10 & - & - & - & - & - & 44 & 12 & 19 & 5 & - & - & - & 1 & 37 & 81 & $54,3 / 45,7$ \\
\hline Abril & 13 & 7 & - & 1 & - & - & - & 21 & 4 & 9 & 5 & 1 & - & - & - & 19 & 40 & $52,5 / 47,5$ \\
\hline Maio & 2 & 1 & - & - & - & - & - & 3 & 6 & 7 & 1 & - & - & - & - & 14 & 17 & $17,6 / 82,4$ \\
\hline Junho & - & - & - & - & - & - & - & - & - & 2 & - & - & - & - & - & 2 & 2 & $-1 / 100$ \\
\hline Julho & - & - & - & - & - & - & - & - & - & - & - & - & - & - & - & - & -2 & $-1-$ \\
\hline Agosto & 2 & 1 & 3 & - & - & - & - & 6 & 3 & 1 & 1 & 1 & - & - & - & 6 & 12 & $50,0 / 50,0$ \\
\hline Setembro & 2 & 3 & - & - & - & - & - & 5 & 1 & 2 & 1 & 1 & - & - & - & 5 & 10 & $50,0 / 50,0$ \\
\hline Outubro & 8 & 2 & - & - & - & - & - & 10 & 4 & - & 1 & - & - & - & 1 & 6 & 16 & $62,5 / 37,5$ \\
\hline Novembro & 3 & - & 1 & - & - & - & - & 4 & - & - & - & - & - & 1 & 1 & 2 & 6 & $66,7 / 33,3$ \\
\hline Total & 119 & 28 & 5 & 1 & - & - & - & 153 & 61 & 68 & 23 & 3 & - & 9 & 3 & 167 & 320 & $47,8 / 52,2$ \\
\hline \multicolumn{19}{|c|}{ C A R A T I N G A } \\
\hline Janeiro & 40 & 1 & 1 & - & 1 & 93 & 1 & 137 & 19 & 1 & 1 & - & - & 39 & - & 60 & 197 & $69,5 / 30,5$ \\
\hline Fevereiro & 22 & 8 & 3 & - & - & 16 & - & 49 & 11 & 9 & 1 & - & - & - & - & 21 & 70 & $70,0 / 30,0$ \\
\hline Março & 10 & 6 & - & - & - & 4 & - & 20 & 5 & 4 & - & - & $\overline{-}$ & - & - & 9 & 29 & $69,0 / 31,0$ \\
\hline Abril & - & 1 & - & - & - & 2 & - & 3 & 4 & 3 & - & - & - & - & 1 & 8 & 11 & $27,31 \quad 72,7$ \\
\hline Maio & 11 & 1 & - & - & 1 & 4 & - & 17 & 10 & 5 & 1 & - & - & - & - & 16 & 33 & $51,5 / 48,5$ \\
\hline Junho & 10 & 8 & 3 & - & 2 & - & - & 23 & - & 13 & 1 & - & 1 & 1 & - & 16 & 39 & $59,0 / 41,0$ \\
\hline Julho & 14 & 15 & 3 & 3 & 6 & - & - & 41 & 4 & 21 & 4 & - & - & - & - & 29 & 70 & $58,6 / 41,4$ \\
\hline Agosto & 8 & 5 & 7 & - & - & - & - & 20 & - & 14 & 3 & 2 & 1 & - & - & 20 & 40 & $50,0 / 50,0$ \\
\hline Setembro & - & - & 6 & 1 & - & 1 & - & 8 & - & 3 & 2 & 1 & - & - & - & 6 & 14 & $57,1 / 42,9$ \\
\hline Outubro & - & - & 1 & 2 & 3 & 157 & - & 163 & - & 7 & 7 & - & 3 & 75 & - & 92 & 255 & $63,9 / 36,1$ \\
\hline Novembro & - & 2 & 3 & 1 & 7 & 40 & - & 53 & - & 1 & - & - & 3 & 46 & - & 50 & 103 & $51,5 / 48,5$ \\
\hline Total & 115 & 47 & 27 & 7 & 20 & 317 & 1 & 534 & 53 & 81 & 20 & 3 & 7 & 162 & 1 & 327 & 861 & $62,0 / 38,0$ \\
\hline
\end{tabular}


TABELA VI - Pesca principal: distribuição de machos e fêmeas de acordo com o grau de maturidade sexual durante 1967 (cont.)

\begin{tabular}{|c|c|c|c|c|c|c|c|c|c|c|c|c|c|c|c|c|c|c|}
\hline \multirow{3}{*}{ Mes } & \multicolumn{8}{|c|}{ MACHOS } & \multicolumn{8}{|c|}{ FEMEAS } & \multicolumn{2}{|c|}{ MACHOS + FEMEAS } \\
\hline & \multirow[b]{2}{*}{ I } & \multicolumn{6}{|c|}{ Grau de Maturidade } & \multirow[b]{2}{*}{ พ9 } & \multicolumn{8}{|c|}{ Grau de Maturidade } & \multirow[b]{2}{*}{ No total } & \multirow[b]{2}{*}{$M / F(z)$} \\
\hline & & II & III & IV & $\mathrm{v}$ & vI & VII & & I & II & III & IV & $\mathbf{v}$ & vI & VII & so & & \\
\hline \multicolumn{19}{|c|}{ CORCOROCA } \\
\hline $\begin{array}{r}\text { Janeiro } \\
\text { Fevereiro } \\
\text { Marco } \\
\text { Abri1 } \\
\text { Maio } \\
\text { Junho } \\
\text { Julho }\end{array}$ & $\begin{array}{r}2 \\
12 \\
8 \\
2 \\
- \\
-\end{array}$ & $\begin{array}{l}z \\
z \\
z \\
z\end{array}$ & $\begin{array}{l}\bar{z} \\
\bar{z} \\
\bar{z}\end{array}$ & $\begin{array}{l}\bar{z} \\
\bar{z} \\
\bar{z}\end{array}$ & $\begin{array}{l}\bar{z} \\
\bar{z} \\
\overline{-}\end{array}$ & $\begin{array}{l}z \\
z \\
z \\
z\end{array}$ & $\begin{array}{l}\bar{z} \\
\bar{z} \\
\bar{z}\end{array}$ & $\begin{array}{r}2 \\
12 \\
8 \\
2 \\
2 \\
-\end{array}$ & $\begin{array}{l}1 \\
5 \\
5 \\
1 \\
1 \\
1\end{array}$ & $\begin{array}{r}1 \\
21 \\
1 \\
2 \\
4 \\
- \\
\end{array}$ & $\begin{array}{l}z \\
z \\
z \\
z\end{array}$ & $\begin{array}{l}z \\
z \\
z\end{array}$ & $\begin{array}{l}z \\
z \\
z\end{array}$ & $\begin{array}{l}z \\
z \\
z \\
z\end{array}$ & $\begin{array}{l}\bar{z} \\
\bar{z} \\
\bar{z}\end{array}$ & $\begin{array}{r}2 \\
-26 \\
1 \\
3 \\
5 \\
1\end{array}$ & $\begin{array}{r}4 \\
-38 \\
38 \\
9 \\
5 \\
7 \\
1\end{array}$ & $\begin{array}{c}50,0 / 50,0 \\
-\overline{31,6 / 68,4} \\
88,9 / 11,1 \\
40,0 / 60,0 \\
28,6 / 71,4 \\
-\quad / 100\end{array}$ \\
\hline Total & 24 & 2 & - & - & - & - & - & 26 & 9 & 29 & - & - & - & - & - & 38 & 64 & $40,6 / 59,4$ \\
\hline \multicolumn{19}{|c|}{ P A R A I I } \\
\hline $\begin{array}{r}\text { Janeiro } \\
\text { Pevereiro } \\
\text { Março } \\
\text { Abri1 } \\
\text { Maio } \\
\text { Junho } \\
\text { Julho } \\
\text { Agosto } \\
\text { Setembro } \\
\text { Outubro } \\
\text { Novembro }\end{array}$ & $\begin{array}{l}= \\
= \\
= \\
1 \\
2 \\
1 \\
= \\
z \\
=\end{array}$ & $\begin{array}{l}= \\
= \\
= \\
= \\
2 \\
1 \\
- \\
2 \\
1\end{array}$ & $\begin{array}{l}\bar{z} \\
\overline{1} \\
- \\
- \\
\bar{z} \\
\overline{2}\end{array}$ & $\begin{array}{l}= \\
= \\
= \\
= \\
= \\
= \\
3 \\
1\end{array}$ & $\begin{array}{l}\overline{5} \\
\overline{5} \\
\bar{z} \\
\bar{z} \\
\overline{2} \\
2\end{array}$ & $\begin{array}{l}1 \\
5 \\
1 \\
5 \\
= \\
= \\
2 \\
2\end{array}$ & $\begin{array}{l}= \\
= \\
\overline{-} \\
\overline{-} \\
\overline{-} \\
=\end{array}$ & $\begin{array}{c}1 \\
- \\
2 \\
2 \\
1 \\
2 \\
3 \\
1 \\
71 \\
11 \\
6\end{array}$ & $\begin{array}{l}3 \\
- \\
- \\
1 \\
1 \\
- \\
5 \\
5 \\
-\end{array}$ & $\begin{array}{r}6 \\
1 \\
2 \\
- \\
3 \\
11 \\
5 \\
13 \\
2 \\
9 \\
4\end{array}$ & $\begin{array}{l}- \\
- \\
3 \\
2 \\
3 \\
4 \\
2 \\
3 \\
3 \\
7 \\
-\end{array}$ & $\begin{array}{l}1 \\
= \\
5 \\
1 \\
1 \\
= \\
= \\
2 \\
-\end{array}$ & $\begin{array}{l}5 \\
\vdots \\
\vdots \\
1 \\
\vdots \\
\vdots \\
1 \\
2\end{array}$ & $\begin{array}{l}1 \\
= \\
= \\
= \\
= \\
= \\
1 \\
4\end{array}$ & $\begin{array}{l}\vdots \\
\vdots \\
2 \\
\vdots \\
\vdots \\
\vdots \\
-\end{array}$ & $\begin{array}{r}11 \\
1 \\
5 \\
4 \\
9 \\
17 \\
7 \\
16 \\
5 \\
20 \\
10\end{array}$ & $\begin{array}{r}12 \\
1 \\
5 \\
6 \\
10 \\
19 \\
10 \\
17 \\
5 \\
31 \\
16\end{array}$ & $\begin{array}{c}8,3 / 91,7 \\
-1100 \\
-\quad 1100 \\
33,3 / 66,7 \\
10,0 / 90,0 \\
10,5189,5 \\
30,0 / 70,0 \\
5,9 / 94,1 \\
-91100 \\
35,5 / 64,5 \\
37,5 / 62,5\end{array}$ \\
\hline Tota1 & 4 & 6 & 3 & 4 & 4 & 6 & - & 27 & 5 & 56 & 27 & 5 & 4 & 6 & 2 & 105 & 132 & $20,5 / 79,5$ \\
\hline \multicolumn{19}{|c|}{ P A R O } \\
\hline $\begin{array}{r}\text { Janeiro } \\
\text { Fevereiro } \\
\text { Março } \\
\text { Abri1 } \\
\text { Maio } \\
\text { Jumho } \\
\text { Julho } \\
\text { Agosto } \\
\text { Setembro } \\
\text { Outubro } \\
\text { Novembro } \\
\end{array}$ & $\begin{array}{l}1 \\
4 \\
3 \\
6 \\
1 \\
- \\
- \\
2 \\
-2 \\
-\end{array}$ & $\begin{array}{l}7 \\
7 \\
2 \\
3 \\
- \\
5 \\
= \\
= \\
= \\
-\end{array}$ & $\begin{array}{l}1 \\
2 \\
1 \\
1 \\
\vdots \\
\vdots \\
\vdots \\
1 \\
-\end{array}$ & $\begin{array}{l}1 \\
\vdots \\
\vdots \\
\vdots \\
\vdots \\
\vdots \\
-\end{array}$ & $\begin{array}{l}\bar{z} \\
z \\
z \\
\vdots \\
z \\
z\end{array}$ & $\begin{array}{l}2 \\
\vdots \\
\vdots \\
\vdots \\
\vdots \\
\vdots \\
2\end{array}$ & $\begin{array}{l}= \\
10 \\
= \\
= \\
= \\
= \\
= \\
=\end{array}$ & $\begin{array}{c}12 \\
23 \\
5 \\
10 \\
1 \\
- \\
- \\
2 \\
- \\
3 \\
2 \\
\end{array}$ & $\begin{array}{l}2 \\
2 \\
1 \\
- \\
\vdots \\
\vdots \\
\vdots \\
= \\
-\end{array}$ & $\begin{array}{l}3 \\
-3 \\
5 \\
1 \\
- \\
- \\
- \\
- \\
1\end{array}$ & $\begin{array}{l}1 \\
5 \\
2 \\
- \\
= \\
- \\
= \\
= \\
= \\
-\end{array}$ & $\begin{array}{l}1 \\
2 \\
= \\
= \\
= \\
= \\
= \\
=\end{array}$ & $\begin{array}{l}\overline{-} \\
\bar{z} \\
\bar{z} \\
\bar{z} \\
\bar{z} \\
1\end{array}$ & $\begin{array}{l}9 \\
5 \\
= \\
= \\
= \\
= \\
= \\
= \\
1\end{array}$ & $\begin{array}{l}\bar{z} \\
1 \\
\vdots \\
\vdots \\
\vdots \\
\vdots \\
-\end{array}$ & $\begin{array}{r}16 \\
14 \\
7 \\
5 \\
1 \\
= \\
= \\
= \\
= \\
3\end{array}$ & $\begin{array}{l}28 \\
37 \\
12 \\
15 \\
2 \\
- \\
- \\
2 \\
- \\
3 \\
5\end{array}$ & 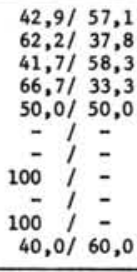 \\
\hline Total & 19 & 19 & 5 & 1 & - & 4 & 10 & 58 & 5 & 13 & 8 & 3 & 1 & 15 & 1 & 46 & 104 & $55,8 / 44,2$ \\
\hline \multicolumn{19}{|c|}{ ROB A L O } \\
\hline $\begin{array}{r}\text { Janeiro } \\
\text { Fevereiro } \\
\text { Março } \\
\text { Abri1 } \\
\text { Maio } \\
\text { Junho } \\
\text { Julho } \\
\text { Agosto } \\
\text { Setembro } \\
\text { Outubro } \\
\text { Novembro }\end{array}$ & $\begin{array}{l}= \\
1 \\
= \\
= \\
= \\
z \\
=\end{array}$ & $\begin{array}{l}\overline{1} \\
-1 \\
1 \\
\vdots \\
= \\
z \\
= \\
=\end{array}$ & $\begin{array}{l}\frac{2}{1} \\
\frac{1}{1} \\
- \\
- \\
- \\
=\end{array}$ & $\begin{array}{l}\bar{z} \\
z \\
z \\
z \\
z \\
z\end{array}$ & 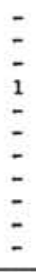 & $\begin{array}{l}1 \\
2 \\
1 \\
1 \\
\vdots \\
\vdots \\
2 \\
\end{array}$ & $\begin{array}{l}z \\
\vdots \\
\vdots \\
z \\
\vdots \\
z \\
-\end{array}$ & $\begin{array}{l}2 \\
2 \\
4 \\
2 \\
2 \\
- \\
= \\
= \\
2 \\
-\end{array}$ & $\begin{array}{l}\bar{z} \\
\bar{z} \\
\bar{z} \\
\bar{z} \\
\overline{-}\end{array}$ & $\begin{array}{l}1 \\
- \\
1 \\
2 \\
- \\
= \\
= \\
-\end{array}$ & $\begin{array}{l}5 \\
2 \\
1 \\
- \\
- \\
- \\
- \\
1 \\
1 \\
- \\
-\end{array}$ & $\begin{array}{l}2 \\
1 \\
1 \\
- \\
\vdots \\
- \\
: \\
= \\
-\end{array}$ & $\begin{array}{l}- \\
- \\
3 \\
1 \\
1 \\
- \\
- \\
5 \\
3 \\
-\end{array}$ & $\begin{array}{l}= \\
= \\
= \\
= \\
= \\
= \\
6 \\
15\end{array}$ & $\begin{array}{l}z \\
z \\
z \\
z \\
z \\
z \\
z\end{array}$ & $\begin{array}{r}8 \\
3 \\
5 \\
2 \\
3 \\
- \\
- \\
1 \\
1 \\
9 \\
15\end{array}$ & $\begin{array}{r}10 \\
5 \\
9 \\
4 \\
5 \\
- \\
- \\
1 \\
1 \\
11 \\
15\end{array}$ & $\begin{array}{c}20,0 / 80,0 \\
40,0 / 60,0 \\
44,4 / 55,6 \\
50,0 / 50,0 \\
40,0 / 60,0 \\
=/ /= \\
=/ 100 \\
=1100 \\
18,2181,8 \\
=1100\end{array}$ \\
\hline Tota1 & 1 & 2 & 4 & - & 1 & 6 & - & 14 & - & 4 & 10 & 4 & 8 & 21 & - & 47 & 61 & $23,0 / 77,0$ \\
\hline \multicolumn{19}{|c|}{$\mathrm{R} O \mathrm{~B} A \mathrm{~L} \tilde{\mathrm{A}} \mathrm{O}$} \\
\hline $\begin{array}{r}\text { Janeiro } \\
\text { Fevereiro } \\
\text { Março } \\
\text { Abri1 } \\
\text { Maio } \\
\text { Junho } \\
\text { Julho } \\
\text { Agosto } \\
\text { Setembro } \\
\text { Outubro }\end{array}$ & $\begin{array}{r}6 \\
2 \\
10 \\
5 \\
9 \\
- \\
= \\
= \\
1\end{array}$ & $\begin{array}{l}2 \\
-2 \\
2 \\
2 \\
2 \\
2 \\
1 \\
1 \\
- \\
-\end{array}$ & $\begin{array}{l}1 \\
- \\
1 \\
- \\
= \\
= \\
=\end{array}$ & $\begin{array}{l}z \\
z \\
z \\
z \\
z \\
z\end{array}$ & $\begin{array}{l}\vdots \\
\vdots \\
\vdots \\
\vdots \\
\vdots\end{array}$ & $\begin{array}{l}5 \\
z \\
z \\
z \\
z \\
z \\
z\end{array}$ & $\begin{array}{l}z \\
\vdots \\
\vdots \\
\vdots \\
\vdots \\
z\end{array}$ & $\begin{array}{r}9 \\
2 \\
12 \\
8 \\
11 \\
2 \\
1 \\
1 \\
-1 \\
1\end{array}$ & $\begin{array}{l}3 \\
1 \\
- \\
2 \\
- \\
- \\
- \\
- \\
-\end{array}$ & $\begin{array}{l}1 \\
2 \\
1 \\
-1 \\
1 \\
= \\
= \\
-\end{array}$ & $\begin{array}{l}\bar{z} \\
\bar{z} \\
z \\
z \\
z \\
z\end{array}$ & $\begin{array}{l}z \\
\overline{-} \\
z \\
z \\
z \\
z\end{array}$ & $\begin{array}{l}z \\
z \\
z \\
z \\
z \\
z\end{array}$ & $\begin{array}{l}= \\
z \\
z \\
z \\
z \\
z\end{array}$ & $\begin{array}{l}z \\
\vdots \\
\vdots \\
\vdots \\
z \\
z\end{array}$ & $\begin{array}{l}4 \\
1 \\
2 \\
3 \\
-1 \\
-1 \\
= \\
=\end{array}$ & $\begin{array}{r}13 \\
3 \\
14 \\
11 \\
11 \\
3 \\
1 \\
1 \\
-1 \\
1\end{array}$ & 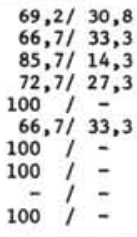 \\
\hline Total & 33 & 12 & 2 & - & - & - & - & 47 & 6 & 5 & - & - & - & - & - & 11 & 58 & $81,0 / 19,0$ \\
\hline \multicolumn{19}{|c|}{$F$ - Fêmea } \\
\hline
\end{tabular}




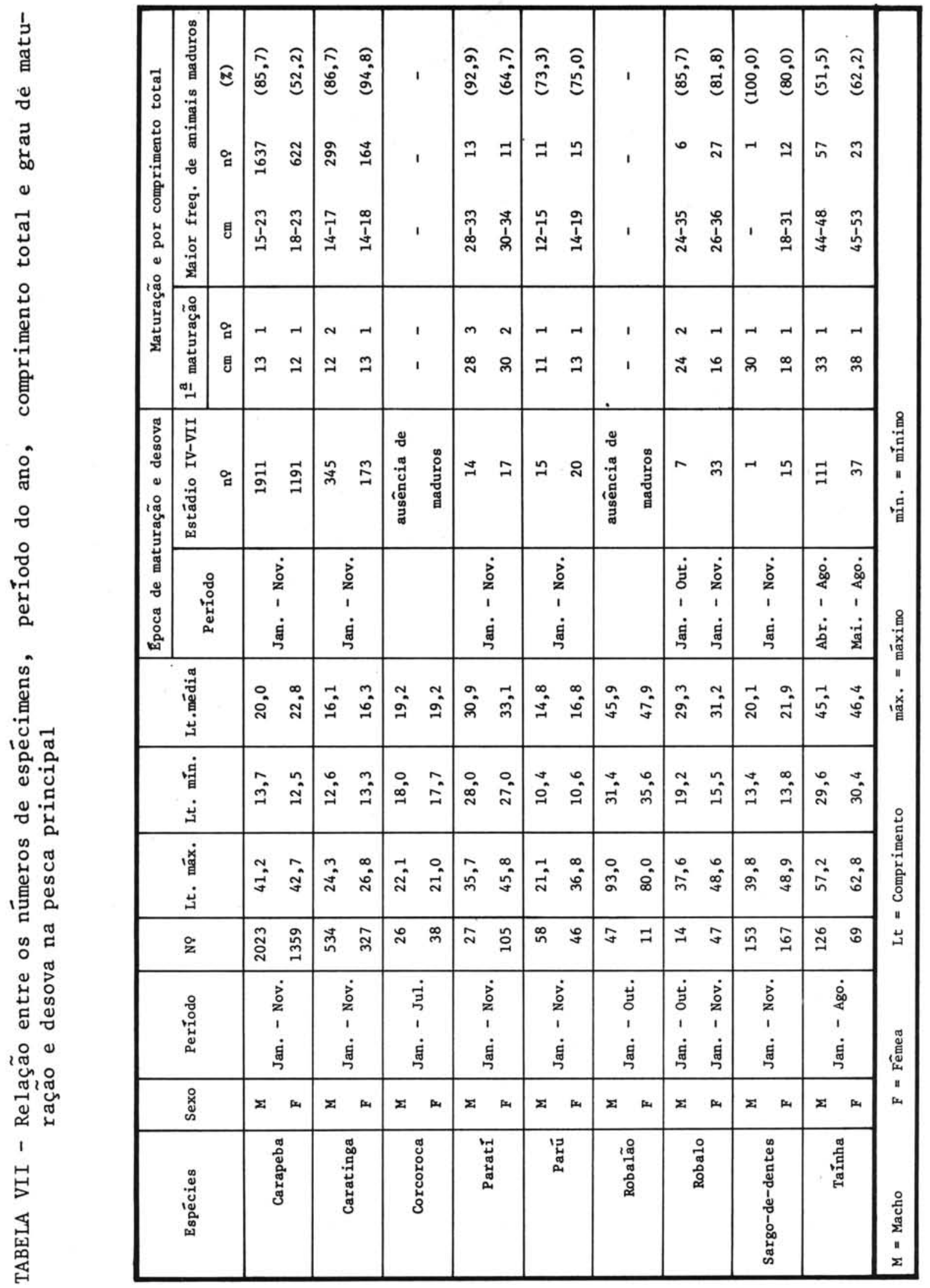



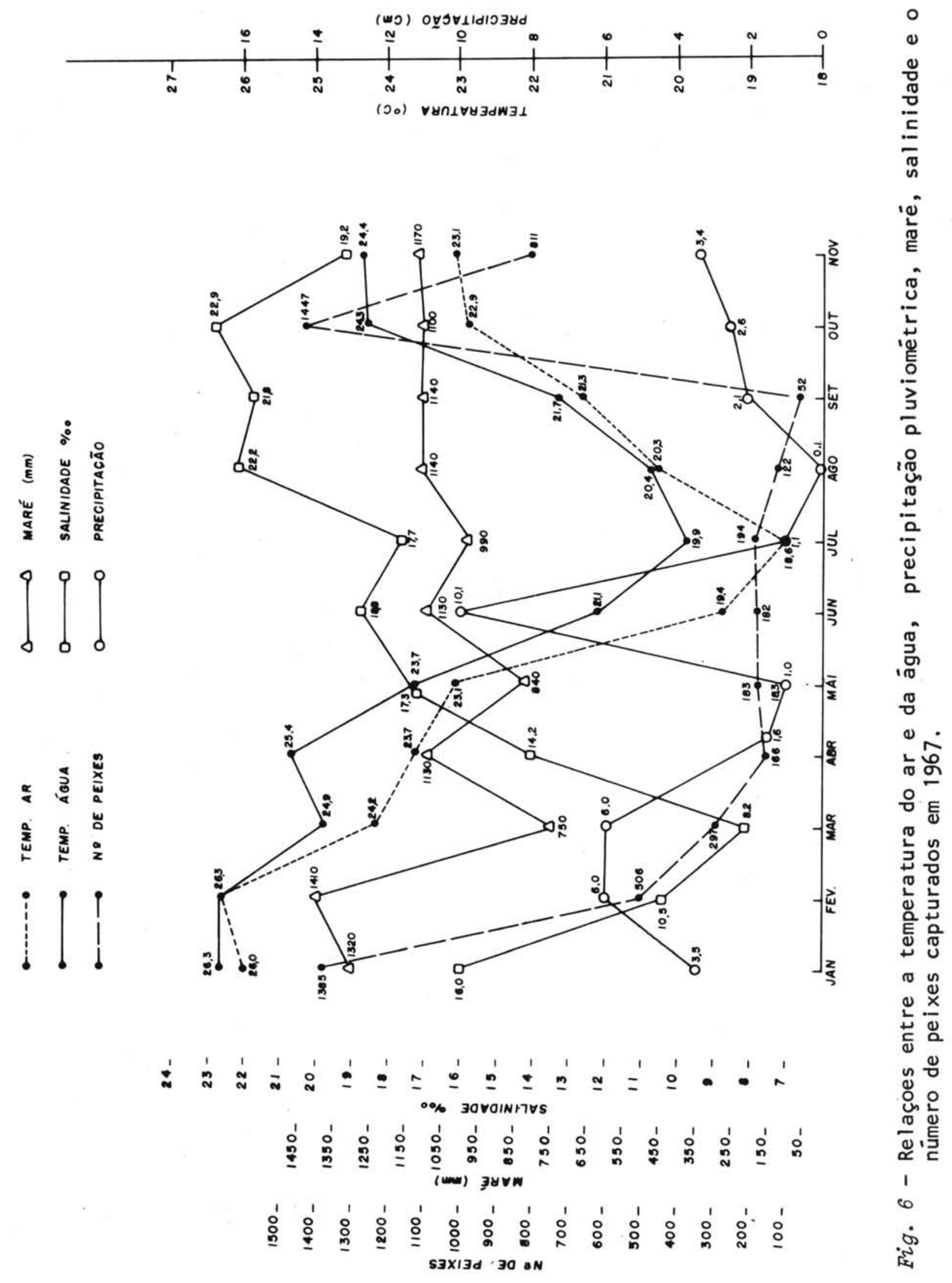


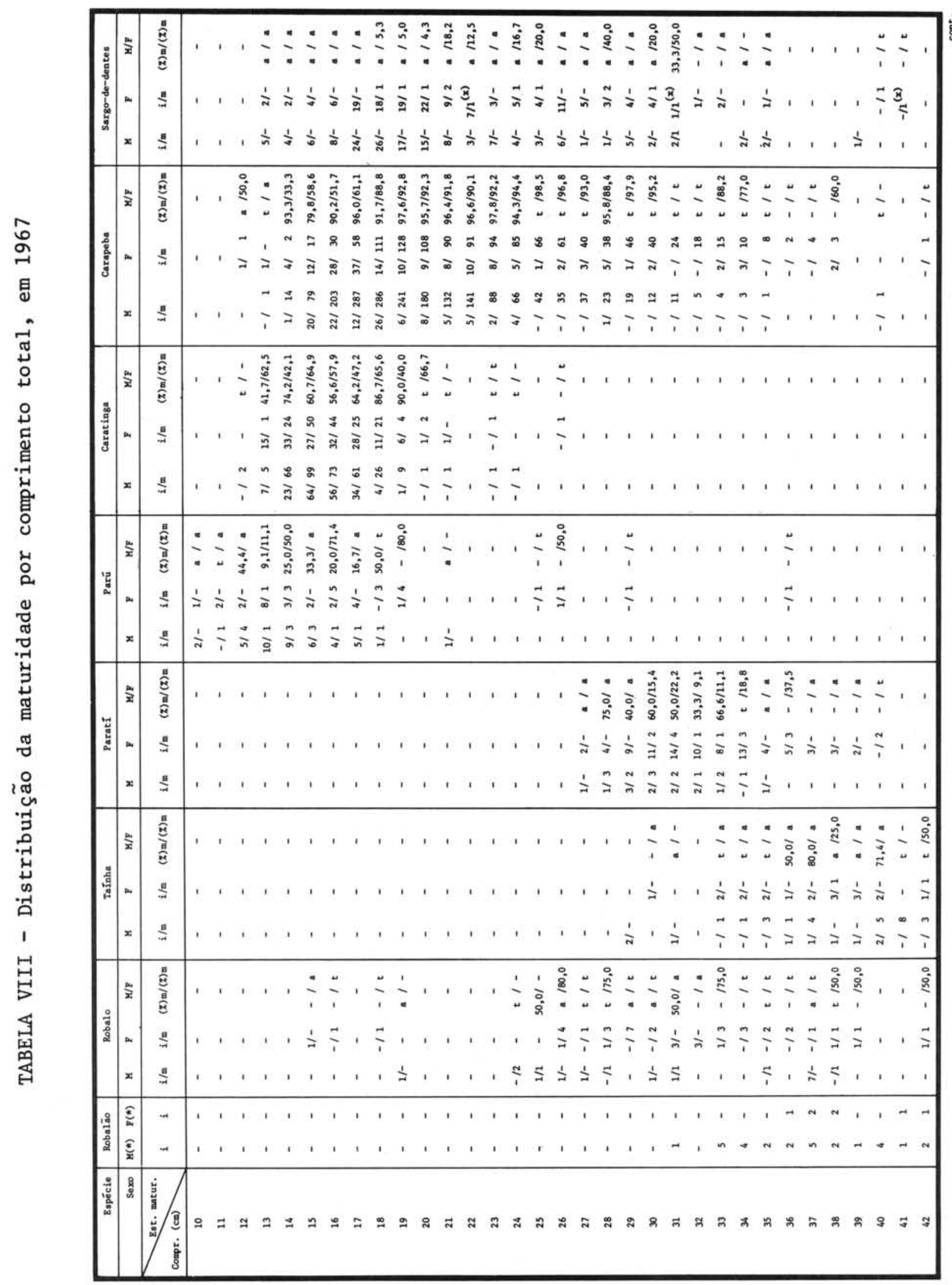




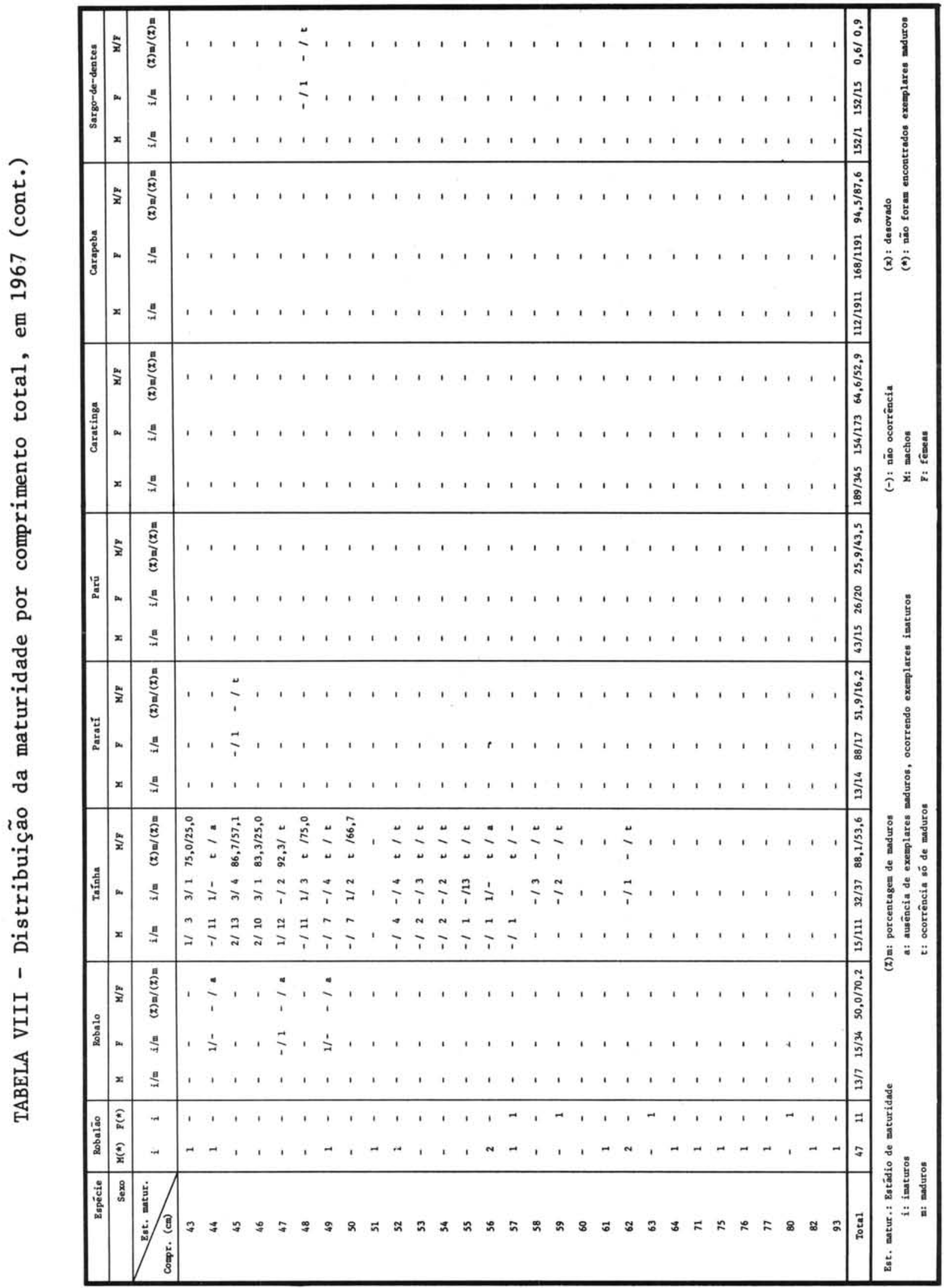


TABELA IX - Salinidade das águas, durante e após grandes chuvas

\begin{tabular}{|c|c|c|c|c|c|c|c|c|c|c|c|c|}
\hline \multicolumn{3}{|c|}{ Loca1: Posto "Cerco Fixo" } & \multicolumn{8}{|c|}{ Profundidade (m) } & \multirow{2}{*}{$\begin{array}{l}\text { Cor da } \\
\text { ägua }\end{array}$} & \multirow{2}{*}{$\begin{array}{c}\text { Precipitação } \\
\text { no momento } \\
\text { da coleta }\end{array}$} \\
\hline Data & Hora & Maré & $\begin{array}{l}\text { Sup. } \\
\mathrm{S} / \mathrm{T}\end{array}$ & $\begin{array}{l}0,5 \\
\text { S/T }\end{array}$ & $\begin{array}{c}1 \\
\mathrm{~S} / \mathrm{T}\end{array}$ & $\begin{array}{c}2 \\
S / T\end{array}$ & $\begin{array}{c}3 \\
\mathrm{~S} / \mathrm{T}\end{array}$ & $\begin{array}{c}4 \\
S / T\end{array}$ & $\begin{array}{c}5 \\
S / T\end{array}$ & $\begin{array}{l}10 \\
S / T\end{array}$ & & \\
\hline 14.01 .63 & $21: 00$ & $\mathrm{v}$ & - & - & - & $4,5 /-$ & - & - & - & - & - & +++ \\
\hline 15.01 .63 & $06: 00$ & E & $2,7 /-$ & - & - & $15,0 /-$ & - & - & - & - & - & +++ \\
\hline 15.01 .63 & $16: 00$ & $\mathrm{v}$ & $3,51-$ & - & - & $11,1 /-$ & - & - & - & - & - & +++ \\
\hline 16.01 .63 & $09: 30$ & $\mathrm{v}$ & $3,21-$ & - & - & $5,5 /-$ & - & - & - & - & - & +++ \\
\hline 11.04 .66 & $08: 30$ & $\mathrm{v}$ & $9,0 / 23,3$ & - & - & - & - & - & - & - & marron & +++ \\
\hline 13.04 .66 & $14: 00$ & $v$ & $4,5 / 25,1$ & - & - & - & - & - & $13,0 / 25,1$ & $24,0 / 25,1$ & marron & +++ \\
\hline 14.04 .66 & $10: 45$ & $\mathrm{E}$ & $7,8 / 25,0$ & $7,9 / 25,0$ & $7,8 /-$ & $7,9 /-$ & $10,0 /-$ & - & - & - & clara & ++ \\
\hline \multicolumn{3}{|c|}{ S = Salinidade $(\% / \%)$} & - Tempera & ura $\left({ }^{\circ} \mathrm{C}\right)$ & $v=v_{c}$ & ante & $E=E n c$ & ente & $++=$ méd & +++ & forte & \\
\hline
\end{tabular}

"Em determinadas épocas, havendo coincidência de curtos períodos chuvosos com fortes cheias do rio, a capacidade evacuadora da Barra de Icaparra é ultrapassada de muito, circunstância que força as águas doces do rio Ribeira de Iguape a invadirem a região da "Pedra do Tombo das Águas" e a se dirigirem para a laguna. Em caminho, essas āguas são acrescidas dos contingentes provenientes dos rios Sabaūna, Cordeiro e Manaú. 0 volume è de tal ordem que as marēs, quando fracas, conseguem apenas vencer os estreitos. As águas salgadas e salobras, pelo menos das superfícies, recuam, ficando a laguna completamente tomada de ägua doce. Nesse momento presencia-se importante fenômeno biológico - todos os representantes de peixes marítimos mesmo os eurialinos, abandonam a laguna, onde a pesca é paralizada. Felizmente, essas inundações são raras e de curta duração".

Kato (1966a) confirma essas observações verificando que as propriedades hidrogrāficas dessas águas são influenciadas pelas flutuações da marē e pelas descargas hỉdricas de terra para a lagoa, completando em um outro 
trabalho (Kato, 1966b) que esta influência de āguas fluviais através dos chamados "Gamboas", depende das variações das suas propriedades com a oscilação da maré. Vê-se, portanto, que a salinidade è grandemente influenciada pelas condições de precipitação pluviométrica e pelo nível da maré, sendo que o conjunto destes fatores afeta o rendimento da pesca de cerco fixo.

\section{CONCLUSÕES}

Das informações obtidas durante as despescas do cerco fixo, foi possîvel verificar que:

1 - A produção em peso do cerco fixo depende principalmente das capturas de duas espécies: carapeba e taînha que acarretam a formação de dois distintos perīodos de produção (de setembro a março e de maio a agosto), nos quais predominam, respectivamente, a carapeba e a taínha.

2 - Das 32 espécies capturadas durante 1967, 9 delas, carapeba, caratinga, corcoroca, paratí, parū, robalão, robalo, sargo-de-dentes e taỉnha, representam o que denominamos de pesca principal, contribuindo com um total de 5.177 espécimens e $846 \mathrm{Kg}$ enquanto as 23 restantes espécies representam uma pesca complementar, fornecendo 168 espécimens e $56 \mathrm{Kg}$.

3 - 0 aparelho de captura utilizado, aprisionou peixes com um comprimento total de $93,0 \mathrm{~cm}$, robalão, e $10,5 \mathrm{~cm}$, parú, e capturou maior quantidade de fêmeas de sargo-de-dentes, caratinga, paratí, parū, robalo e corcoroca, sendo que o oposto ocorreu com carapeba, robalão e taỉnha.

4 - Os exemplares capturados no presente estudo apresentaram as seguintes características com respeito ao comprimento total por sexo: para 
carapeba, taînha, sargo-de-dentes, parú, paratí, robalo e robalão as fêmeas apresentaram maior comprimento total que os machos, não sendo evidenciadas diferenças entre machos e fêmeas de parū e corcoroca.

5 - Ocorreram exemplares maduros de taínha nos meses de abril e agosto, sugerindo a possibilidade de desova neste período. Os exemplares de parú, paratí, robalo e sargo-de-dentes, apresentaram-se maduros quase todo o ano o que parece indicar a ocorrência de um amplo período de desova. Não foram encontrados exemplares maduros de robalão e corcoroca.

6 - Observou-se que o comprimento médio de início da primeira maturação sexual, respectivamente para machos e fêmeas, foi: carapeba, 13 e $12 \mathrm{~cm}$; caratinga, 12 e $13 \mathrm{~cm}$; paratí, 28 e $30 \mathrm{~cm}$; parū, 11 e $13 \mathrm{~cm}$; robélo, 24 e $16 \mathrm{~cm}$; taínha, 33 e $38 \mathrm{~cm}$ e $18 \mathrm{~cm}$ para as fêmeas de sargo-de-dentes.

7 - A produção quantitativa e qualitativa de peixes na captura do cerco localizado na região lagunar de Cananéia è influenciada pelas condições hidrogrāficas locais, principalmente pela temperatura e salinidade da ägua.

8 - A produção de taínha parece relacionada com o decréscimo da temperatura da āgua, ocorrendo em maior abundância quando a temperatura média mensal da água é inferior a $24^{\circ} \mathrm{C}$. A produção de carapeba ocorre em períodos nos quais a temperatura da āgua ē mais elevada.

9 - A salinidade da água influi de maneira marcante na produção do cerco durante os períodos de intensas chuvas e de grandes enchentes do rio Ribeira de Iguape, ocorrendo nessa época condições que permitem atē o aparecimento de peixes típicos de água doce, nas despescas do cerco.

10 - A pesca comercial efetuada regionalmente com este aparelho de captura, è orientada para o período de maior produção pesqueira, que parece coincidir com a maturação sexual da taỉnha. De uma maneira geral a produção obtida ē baixa e comercialmente falando só é interessante nessa época. 


\section{AGRADECIMENTOS}

Ao Sr. Dr. Victor Sadowsky, chefe da Base Sul do Instituto Oceanogräfico, em Cananéia, pela sugestão do tema, conselhos e ajuda prática no presente trabalho.

Aos Srs. Dr. Sergio Araujo Antunes e Alfredo Tenuta Filho, da Secção de Quî́mica da Divisão de Tecnologia do Instituto Oceanogrä́fico da Universidade de São Paulo, pela ajuda na redação deste trabalho.

A Sra. Dra. Anna Emília Amato de Moraes Vazzoler, e aos Srs. Lic. Alfredo Martins Paiva Filho e Bach. Yasunobu Matsuura, pela correção da redação final, pela elaboração de grāficos e tabelas.

A Secção de Química e Sedimentologia do Instituto Oceanogräfico pelas análises de oxigênio e salinidade.

E a todo pessoal auxiliar da Base Sul em Cananéia, do Instituto Oceanogräfico da Universidade de São Paulo.

\section{B IBLIOGRAF IA}

BESNARD, W. 1950a. Considerações gerais em torno da região lagunar de Cananéia - Iguape. I. Bolm Inst. paul. Oceanogr., 1(1):9-26.

1950b. Considerações gerais em torno da região lagunar de Cananéia - Iguape. II. Diversos aspectos atuais da região lagunar. Bolm Inst. paul. Oceanogr., 1(2):3-28.

BRANDT, A. von 1959. Classification of fishing gear. In: Kristjonsson, H., ed. - Modern fishing gear of the world, Section 9:274-296. London, Fishing News (Books) Ltd. 
KATO, K. 1966a. Geochemical studies on the mangrove region of Cananeia. Brazil. I. Tidal variations of water properties. Bolm Inst. oceanogr., S Paulo, 15(1):13-20.

1966b. Chemical investigations on the hydrographical system of Cananéia lagoon. Bolm Inst. oceanogr., S Paulo, 15(1):1-12.

MACHADO, L. B. 1950. Pesquisas físicas e químicas do sistema hidrográfico da região lagunar de Cananéia. I. Curso de águas. Nota prévia sobre os rios: Maria Rodrigues e Baguaçu. Bolm Inst. paul. Oceanogr., $1(1): 45-68$. figs. wap.

MEISSNER, W. T. 1933. Promislowaia Ichtiologia. Moskwa - Leningrad "Snabtechysdat" p. 191.

(Recebido em 12/Setembro/1974) 